\section{OPEN ACCESS}

Edited by:

Gilles Reverdin,

Centre National de la Recherche

Scientifique (CNRS), France

Reviewed by:

James Potemra,

University of Hawai'i at Mānoa,

United States

Tangdong Qu,

University of California, Los Angeles,

United States

*Correspondence:

Janet Sprintall

jsprintall@ucsd.edu

Specialty section:

This article was submitted to

Ocean Observation,

a section of the journal

Frontiers in Marine Science

Received: 14 November 2018

Accepted: 30 April 2019

Published: 04 June 2019

Citation:

Sprintall J, Gordon AL, Wijffels SE, Feng M, Hu S, Koch-Larrouy A, Phillips $H$, Nugroho D, Napitu A, Pujiana K, Susanto $R D$, Sloyan $B$, Peña-Molino B, Yuan D, Riama NF, Siswanto S, Kuswardani A, Arifin Z,

Wahyudi AJ, Zhou H, Nagai T,

Ansong JK, Bourdalle-Badié $R$,

Chanut J, Lyard F, Arbic BK, Ramdhani A and Setiawan A (2019)

Detecting Change in the Indonesian

Seas. Front. Mar. Sci. 6:257.

doi: 10.3389/fmars.2019.00257

\title{
Detecting Change in the Indonesian Seas
}

\begin{abstract}
Janet Sprintall ${ }^{1 *}$, Arnold L. Gordon ${ }^{2}$, Susan E. Wijffels ${ }^{3}$, Ming Feng ${ }^{4,5}$, Shijian Hu ${ }^{6,7}$, Ariane Koch-Larrouy 8,9 , Helen Phillips ${ }^{10}$, Dwiyoga Nugroho 8,11 , Asmi Napitu ${ }^{12}$, Kandaga Pujiana ${ }^{13}$, R. Dwi Susanto ${ }^{13,14}$, Bernadette Sloyan ${ }^{4,5}$, Beatriz Peña-Molino ${ }^{4,5}$, Dongliang Yuan ${ }^{6,7}$, Nelly Florida Riama ${ }^{15}$, Siswanto Siswanto ${ }^{15}$, Anastasia Kuswardani ${ }^{12}$, Zainal Arifin ${ }^{16}$, A'an J. Wahyudi ${ }^{16}$, Hui Zhou ${ }^{6}$, Taira Nagai ${ }^{17}$, Joseph K. Ansong ${ }^{18}$, Romain Bourdalle-Badié 9 , Jerome Chanut ${ }^{8}$, Florent Lyard ${ }^{8}$, Brian K. Arbic ${ }^{19}$, Andri Ramdhani ${ }^{15}$ and Agus Setiawan ${ }^{12}$
\end{abstract}

\begin{abstract}
${ }^{1}$ Scripps Institution of Oceanography, University of California, San Diego, La Jolla, CA, United States, ${ }^{2}$ Lamont Doherty Earth Observatory of Columbia University, Palisades, NY, United States, ${ }^{3}$ Department of Physical Oceanography, Woods Hole Oceanographic Institution, Woods Hole, MA, United States, ${ }^{4}$ Commonwealth Scientific and Industrial Research Organisation (CSIRO), Hobart, TAS, Australia, ${ }^{5}$ Centre for Southern Hemisphere Oceans Research, Hobart, TAS, Australia, ${ }^{6}$ Key Laboratory of Ocean Circulation and Waves, Institute of Oceanology, Center for Ocean Mega-Science, Chinese Academy of Sciences, Qingdao, China, ${ }^{7}$ Qingdao National Laboratory for Marine Science and Technology, Qingdao, China, ${ }^{8}$ Laboratory of Studies on Spatial Geophysics and Oceanography (LEGOS), Toulouse, France, ${ }^{9}$ Mercator-Océan, Ramonville-Saint-Agne, France, ${ }^{10}$ Institute for Marine and Antarctic Science, University of Tasmania, Hobart, TAS, Australia, ${ }^{11}$ Agency of Research and Development for Marine and Fisheries, Jakarta, Indonesia, ${ }^{12}$ Ministry of Marine Affairs and Fisheries of the Republic of Indonesia, Jakarta, Indonesia, ${ }^{13}$ Faculty of Earth Sciences and Technology, Bandung Institute of Technology, Bandung, Indonesia, ${ }^{14}$ Department of Atmospheric and Oceanic Science, University of Maryland, College Park, MD, United States, ${ }^{15}$ Meteorology, Climatology, and Geophysical Agency (BMKG), Jakarta, Indonesia, ${ }^{16}$ Research Center for Oceanography, Indonesian Institute of Sciences (LIPI), Jakarta, Indonesia, ${ }^{17}$ Department of Earth and Planetary Science, The University of Tokyo, Tokyo, Japan, ${ }^{18}$ Department of Mathematics, University of Ghana, Legon, Ghana, ${ }^{19}$ Department of Earth and Environmental Sciences, University of Michigan, Ann Arbor, MI, United States
\end{abstract}

The Indonesian seas play a fundamental role in the coupled ocean and climate system with the Indonesian Throughflow (ITF) providing the only tropical pathway connecting the global oceans. Pacific warm pool waters passing through the Indonesian seas are cooled and freshened by strong air-sea fluxes and mixing from internal tides to form a unique water mass that can be tracked across the Indian Ocean basin and beyond. The Indonesian seas lie at the climatological center of the atmospheric deep convection associated with the ascending branch of the Walker Circulation. Regional SST variations cause changes in the surface winds that can shift the center of atmospheric deep convection, subsequently altering the precipitation and ocean circulation patterns within the entire Indo-Pacific region. Recent multi-decadal changes in the wind and buoyancy forcing over the tropical Indo-Pacific have directly affected the vertical profile, strength, and the heat and freshwater transports of the ITF. These changes influence the largescale sea level, SST, precipitation and wind patterns. Observing long-term changes in mass, heat and freshwater within the Indonesian seas is central to understanding the variability and predictability of the global coupled climate system. Although substantial progress has been made over the past decade in measuring and modeling the physical and biogeochemical variability within the Indonesian seas, large uncertainties remain. A comprehensive strategy is needed for measuring the temporal and spatial scales of variability that govern the various water mass transport streams of the ITF, its connection 
with the circulation and heat and freshwater inventories and associated air-sea fluxes of the regional and global oceans. This white paper puts forward the design of an observational array using multi-platforms combined with high-resolution models aimed at increasing our quantitative understanding of water mass transformation rates and advection within the Indonesian seas and their impacts on the air-sea climate system.

Keywords: Indonesian throughflow, observing system, intraseasonal, ENSO, transport variability, planetary waves

\section{INTRODUCTION}

The transfer of water from the Pacific to Indian Ocean via the Indonesian seas, known as the Indonesian Throughflow (ITF), is the only tropical pathway for exchange between ocean basins in the global circulation (Figure 1). Pacific waters passing through the Indonesian seas are mixed, cooled and freshened and transformed into unique water masses that can be tracked across the Indian Ocean basin and beyond. The Indonesian seas also lie at the climatological center of the atmospheric deep convection associated with the ascending branch of the Walker Circulation and, as such, play a central role in the climate system. The western node of sea surface temperature (SST) anomalies associated with the El Niño-Southern Oscillation (ENSO) and the eastern node of SST anomalies associated with the Indian Ocean Dipole (IOD) are collocated within the Indonesian seas. The regional SST variations of these major climate oscillations cause changes in the surface winds that may shift the center of atmospheric deep convection, subsequently altering the precipitation and ocean circulation patterns within the entire Indo-Pacific region. Moreover, model studies demonstrate that proper representation of the coupled dynamics between the SST and wind over the Indonesian seas is required for a more realistic simulation of ENSO (Wittenberg et al., 2006; Neale et al., 2008; Annamalai et al., 2010; Koch-Larrouy et al., 2010). Thus, observing the changes in mass, heat and freshwater storage and transfer within the Indonesian seas is central to monitoring and understanding fluctuations in the large-scale ocean and climate systems.

Quantitative knowledge of ITF behavior is of fundamental importance to a wide range of end users including ocean and climate research as well as being of direct societal benefit. Ocean circulation and processes in the Indonesian seas influence not only the local climate but also the global climate through teleconnections with the Pacific and Indian Ocean. Data from the Indonesian seas is therefore of vital importance to regional forecasts and for data assimilation model efforts. Anomalies in the Indo-Pacific SST affect regional rainfall and drought patterns in the many Indian Ocean rim countries that are particularly vulnerable to climate change. Changes in the physical properties of the water are linked to the behavior, migration pattern and the seasonal distribution of the phytoplankton and pelagic fish species that live within the Indonesian seas. The maritime continent is one of the most important reservoirs of marine biodiversity on the planet, which encourages abundant activities in fisheries, aquaculture and tourism. Thus, the necessity of monitoring and forecasting the ITF pathways and variability is significant for the region's people, who depend on the sea for their food and livelihood, and also to help develop management plans to sustain these valuable and limited maritime resources. Understanding the coupled air-sea system in the Indonesian seas is therefore of relevance for regional climate, water resources, and ultimately to the largely agrarian based society through impacts on agriculture, economies, fisheries, and health.

The Ocean Obs '09 (OO'09) white paper (Gordon et al., $2010 \mathrm{~b}$ ) that discussed ITF observations coincided with the release of the first-look papers describing the simultaneous measurements of the velocity and property variability in the major inflow and outflow ITF passages undertaken as part of the International Nusantara Stratification and Transport (INSTANT) program (Gordon et al., 2008; Sprintall et al., 2009). INSTANT measurements provided an estimate of mean ITF transport of $15 \mathrm{~Sv}$ into the Indian Ocean, about 30\% higher than estimates made from non-simultaneous measurements prior to INSTANT. This first directly observed estimate of the total ITF transport is a definitive benchmark for global and coupled models, and thus has been extensively cited in the ensuing literature. INSTANT revealed many previously undocumented major features of the ITF. In contrast to earlier expectations, INSTANT found that the transport profile in some straits could have a subsurface maximum within the thermocline, with a seasonal phasing and depth level that varied from strait to strait. The vertical profile of the volume transport through each strait sets the heat flux carried by the ITF and cannot be deduced without direct measurement. INSTANT revealed complex variability in the ITF: local and remote wind forcing; tides; intraseasonal to interannual fluctuations; and a plethora of planetary waves that radiate and scatter into the Indonesian seas affecting the currents and mixing. Though capturing this complexity, INSTANT made it obvious that simultaneous measurements in the major inflow and outflow passages are required to accurately depict the full ITF.

While the highly successful INSTANT program delivered a step change in our understanding of the ITF, this program ended more than 10 years ago. In the ensuing years, significant changes have occurred in the Indo-Pacific system, and likely also the ITF, as detected in a few limited direct measurements but mainly inferred from changes downstream in the Indian Ocean. In addition, there are critical phenomena and passages that INSTANT did not resolve well. Consequently, large uncertainties remain in our current understanding of the ITF and its impact on regional SST and the Pacific and Indian Oceans.

In this white paper, we will first present new results (since Gordon et al., 2010b) from recent monitoring programs that have measured aspects of the ITF from its Pacific source, through the Indonesian internal seas, and out through the exit passages into the Indian Ocean. In particular we highlight how recent 


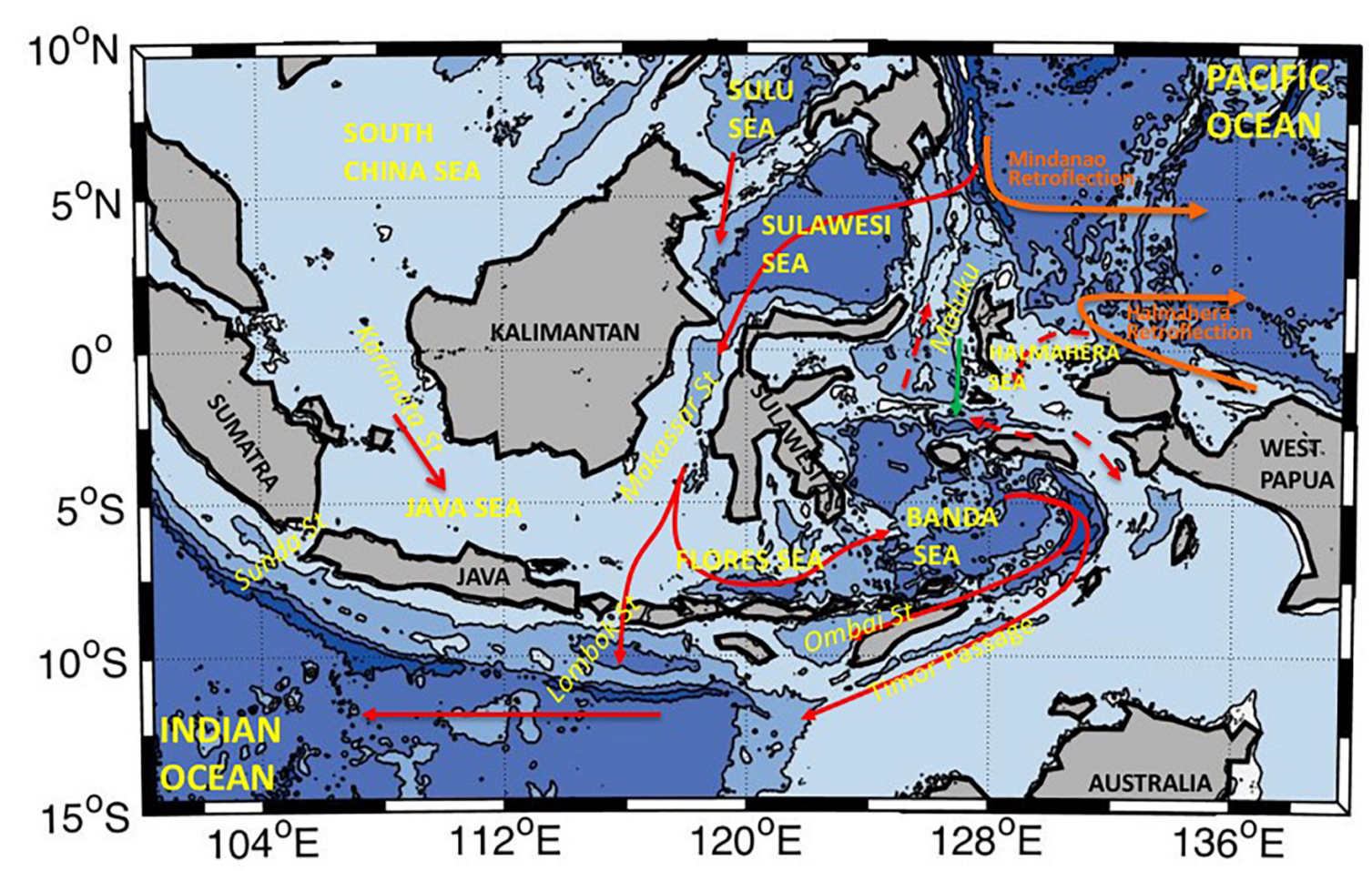

FIGURE 1 | Map of the Maritime Continent, a schematic of the main ITF currents, seas and basins discussed in the text. Upper ocean current pathway is in red, lower pathway in green. Dashed lines indicate uncertain pathways.

changes in the wind and buoyancy forcing over the tropical IndoPacific have directly affected the vertical profile, strength, and the heat and freshwater transports of the ITF. We will then discuss the recent direct observations and models that show the tidally driven mixing within the Indonesian seas strongly modifies the temperature and salinity profiles and affects the overall character of the ITF. Finally, anticipated sustained monitoring efforts of the ITF and its associated heat and freshwater fluxes are identified through examination of the strengths and challenges in developing an ITF observing system, taking advantage of emerging new technologies. We conclude by proposing a strategy for an integrated observing array that exploits multiple platforms. As such, this paper connects to the OO'19 vital conference theme of Climate Variability and Change and addresses the underlying theme of Observing Technologies and Networks.

\section{CURRENT STATUS OF THE OBSERVING SYSTEM IN THE INDONESIAN SEAS}

\section{Introduction}

The Indonesian seas provide a complex gateway from the Pacific to Indian Ocean via a myriad of narrow channels connecting seas and basins of varying depths and sizes (Figure 1). The primary inflow channeling the tropical North Pacific water through the Indonesian seas is within Makassar Strait, carrying about $~ 80 \%$ (12-13 Sv) of the total ITF (Susanto and Gordon, 2005; Gordon et al., 2010a). The remainder of the ITF enters via the more porous eastern passages of the Indonesian seas via the Maluku Sea, with a South Pacific contribution mostly entering through the Halmahera Sea, as well as a density-driven overflow through Lifamatola Passage that ventilates the deeper layers of the Banda Sea. Smaller amounts (1-2 Sv) are injected by direct inflow from the South China Sea (SCS) via Karimata Strait (Fang et al., 2010; Susanto et al., 2013) and through the Sibutu Passage into the Sulawesi Sea that draws water from the Sulu Sea derived from the SCS (Gordon et al., 2012). The ITF exits into the Indian Ocean primarily through gaps along the Nusa Tengarra island chain, but mostly through Lombok Strait, Ombai Strait and Timor Passage. There is likely a small amount of exchange occurring across the shallow but broad Australian Northwest Shelf. Downstream in the tropical Indian Ocean, the ITF sustains a narrow relatively cool, low salinity streak in the upper thermocline (Gordon et al., 1997) and a distinctly different core of high silicate, low salinity intermediate ITF waters (Talley and Sprintall, 2005).

Trade winds over the western Pacific and the Australian Indonesian monsoon winds together maintain a pressure difference between the Pacific and Indian Ocean, that generally regulates the mean ITF (Wyrtki, 1987). The transient component of the winds over the equatorial Pacific and Indian Oceans affect the inter-basin pressure difference through the formation of planetary waves and hence contribute to the variability of the ITF on a broad range of timescales. Annual equatorial Rossby waves originating in the eastern Pacific Ocean propagate westward across the tropical Pacific Ocean and modulate sea surface height over the western boundary of the Pacific, that 
in turn contribute to seasonal variations of the interocean pressure gradient and subsequently the ITF (Potemra, 1999). The equatorial Rossby and Kelvin waves respectively, impinge upon the western boundary of the Pacific and the eastern boundary of the Indian Ocean (the "Wyrtki Jet"; Wyrtki, 1973), forming coastal Kelvin waves that penetrate into the Indonesian seas and modulate the ITF (Wijffels and Meyers, 2004). Over the equatorial Indian Ocean, strong wind transitions force upwelling and downwelling equatorial Kelvin waves on intraseasonal, semi-annual and interannual time scales that dictate variations of the ITF (Sprintall et al., 2000; Pujiana et al., 2009, 2013; Drushka et al., 2010; Yuan et al., 2011, 2013; Shinoda et al., 2012).

The ITF also experiences substantial interannual variations, influenced by the Indian and Pacific wind forcing. It is expected that when the Pacific wind stress is weak or reversed during El Niño conditions, that this would lead to a weaker ITF, and viceversa under La Niña conditions. However, in reality the ENSO relationship to transport is not clear cut in all the passages. Part of the complication lies because no two ENSO events are the same, and part also lies with whether the ENSO is concurrent (or not) with IOD events that also have a strong impact on the ITF transport. It is critical to understand climate variability at interannual time scales since they can mask and complicate interpretation of the long-term trends and decadal variability. The interannual to decadal behavior of the ITF and how well this is simulated in seasonal to climate models remains a major research challenge.

Since OO'09, we have uncovered fresh knowledge about the variability of the ITF and the nature of the processes that cause that variability. The in situ observations maintained over the past decade in the Indonesian seas that have contributed to this understanding are listed in the Supplementary Table 1. The observational evidence supported by models show that recent changes in the Indo-Pacific wind and buoyancy forcing have dramatically affected the vertical profile and flow through the Indonesian seas. In addition, recent studies focused on intraseasonal variability in the Indonesian seas have intensified, motivated in part by the international Years of the Maritime Continent (YMC) project. Finally, we discuss decadal and longer term variability that while mostly observed in the Indian Ocean, can be attributed to long-term ITF influence. This section highlights these and other new findings.

\section{Variability in Observed Pathways of the ITF Makassar Strait}

There are now $\sim 13.5$ years of measurements of the Makassar Strait throughflow within the Labani Channel constriction (sill depth $\sim 680 \mathrm{~m}$ ) (Figure 2A) constituting the longest time series in any stream of the ITF (Gordon et al., 2019). The complete record attests to the power and insight afforded by extended time series. The growth of the time series has enabled a more quantitative detection of the variability over a broad range of time scales.

An unexpected attribute of the Makassar Strait throughflow is that the strongest southward flow is not within the warm sea surface layer but rather within the cooler thermocline (Figure 2). The likely cause of the subsurface velocity maximum is the injection of buoyant, low salinity surface water drawn into Makassar Strait from the SCS and Java Sea (Gordon et al., 2003, 2012; Tozuka et al., 2007, 2009; Fang et al., 2010; Susanto et al., 2010, 2013) as well as from Sunda Strait (Susanto et al., 2016). This buoyant layer creates a "freshwater plug" that inhibits the inflow of tropical Pacific surface water from the Mindanao Current. The SCS effect in the upper $\sim 100 \mathrm{~m}$ is strongest during boreal winter and extends into spring, albeit with distinct interannual variability. Stronger southward flow within Makassar Strait occurs in the upper $300 \mathrm{~m}$ during the boreal summer.

The Madden-Julian Oscillation (MJO) and shear instabilitygenerated eddies together dictate intraseasonal variations in the upper $200 \mathrm{~m}$ of the Makassar Strait throughflow (Pujiana et al., 2012; Napitu, 2017; Napitu et al., 2019). The MJO is strongest during boreal winter monsoon across the Indonesian seas (Napitu et al., 2015). During boreal winter the MJO is thought to weaken the Pacific to Indian Ocean pressure gradient and so increase the northward (toward the Pacific Ocean) momentum transfer from wind stress. In turn, this induces monthly pulses of northward along-strait flow in the surface layer in Makassar Strait resulting in a substantial reduction of the ITF transport in the upper layer of Makassar Strait (Napitu, 2017, Napitu et al., 2019). Increased turbulent stress at the base of the upper layer also acts to decelerate the anomalous ITF transport toward the Pacific Ocean during MJO events. This contributes to the seasonal reduction of the southward throughflow (Napitu, 2017; Napitu et al., 2019). Indian Ocean Kelvin waves are identifiable from the observations as northward flows beneath $200 \mathrm{~m}$ (Figure 2), acting to regulate the intraseasonal and semi-annual (May and November) variability in Makassar Strait (Pujiana et al., 2009, 2013; Susanto et al., 2012).

Interannual variability in Makassar Strait scales roughly to ENSO, with reduced transport and a deeper and weaker maximum velocity during El Niño and stronger southward flow with shallower stronger maximum velocity during La Niña (Figure 3; Gordon et al., 2010b, 2012; Susanto et al., 2012). The 13-year time series shows a prolonged shoaling and strengthening of the ITF since 2007 (Figure 2; Gordon et al., 2012). The thermocline velocity maximum shifted from 140 to $70 \mathrm{~m}$ depth and velocity increased from 70 to $90 \mathrm{~cm} / \mathrm{s}$. Models suggest that this might be related to ENSO events that control the presence of buoyant freshwater pools in the inflow region and so act to modulate the surface layer contribution to the Makassar throughflow via the "freshwater plug" (Gordon et al., 2012).

Since 2016 the deep layer (300-760 m) southward transport has increased, almost doubling to $\sim 7.5 \mathrm{~Sv}$ (Figure 4). From late 2016 into early 2017 the transport above $300 \mathrm{~m}$ and below $300 \mathrm{~m}$ are about equal, whereas there is usually a ratio of $2: 1$. In early 2017 the total Makassar transport reached an 'historical' high of over 20 Sv. A particularly strong surface layer reversal is observed in the winters of 2014/15 and 2016/17 - the latter is the strongest winter reversal revealed in the Makassar time series (Pujiana et al., 2019). In June/July 2016 there is a marked relaxation of the southward flow within the thermocline, dividing the summer maximum into two separate features. During this event the ITF 

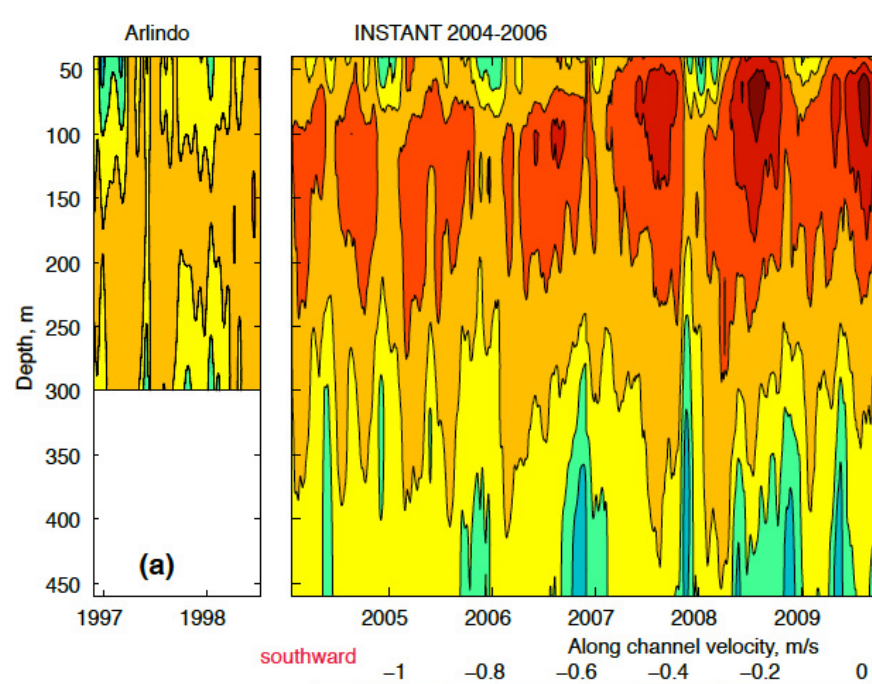

MITF 2007 - continuing

FIGURE 2 | Time series of currents (m/s; 30-day running average), from 50 to $450 \mathrm{~m}$ depth, along the axis of Labani Channel of Makassar Strait. Red colors are toward the south (Indian Ocean), blue colors to the north (Figure from Gordon et al., 2019).
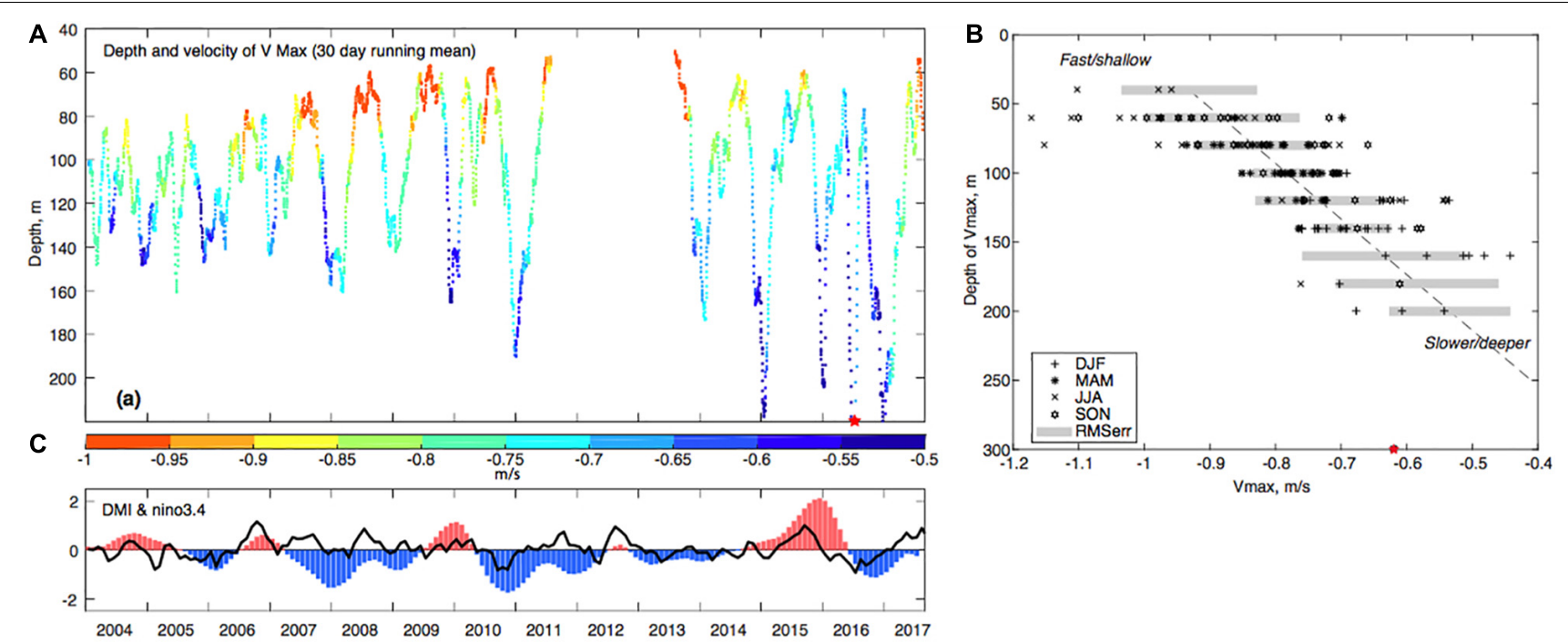

FIGURE 3 | (A) Time series of depth of the velocity maximum (Vmax) from the mooring within Labani Channel of Makassar Strait, color coded by speed (m/s). An anomalous deep Vmax occurred in June/July 2016, which is likely the imprint of a strong Kelvin Wave intrusion from the Indian Ocean. (B) The IOD (black line) and Nino3.4 Index (blue: la Niña; red: el Niño) over the same period as the mooring deployment. (C) Scatter plot of Depth of Vmax versus Vmax stratified by season (Figure from Gordon et al., 2019).

is northward, a condition that in prior years was seen only in the boreal winter. Anomalously strong boreal summer MJO events may be the cause of this unusual relaxation of the ITF in the upper layer in June 2016, while the flow in the lower thermocline is impacted by an anomalously strong Wyrtki-jet in the Indian Ocean that forced a northward propagating Kelvin wave through Makassar Strait (Pujiana et al., 2019).

The Makassar southward heat flux anomaly (relative to a mean heat flux referenced to $0^{\circ} \mathrm{C}$; Gruenburg and Gordon, 2018) increased rapidly from 2006 to 2008 with a peak of $0.13 \mathrm{PW}$ in 2008 and 2009. Makassar heat flux anomaly then slowly decreased to a minimum of -0.22 PW during 2015 before climbing again in recent years. The heat content anomaly in the eastern tropical Indian Ocean, determined from Argo profiles, follows a similar pattern to the Makassar heat flux anomaly with a lag of 2 to 3 years.

\section{Eastern Passages}

The circulation at the entrance of the Indonesian seas is characterized by two western boundary currents, the North 

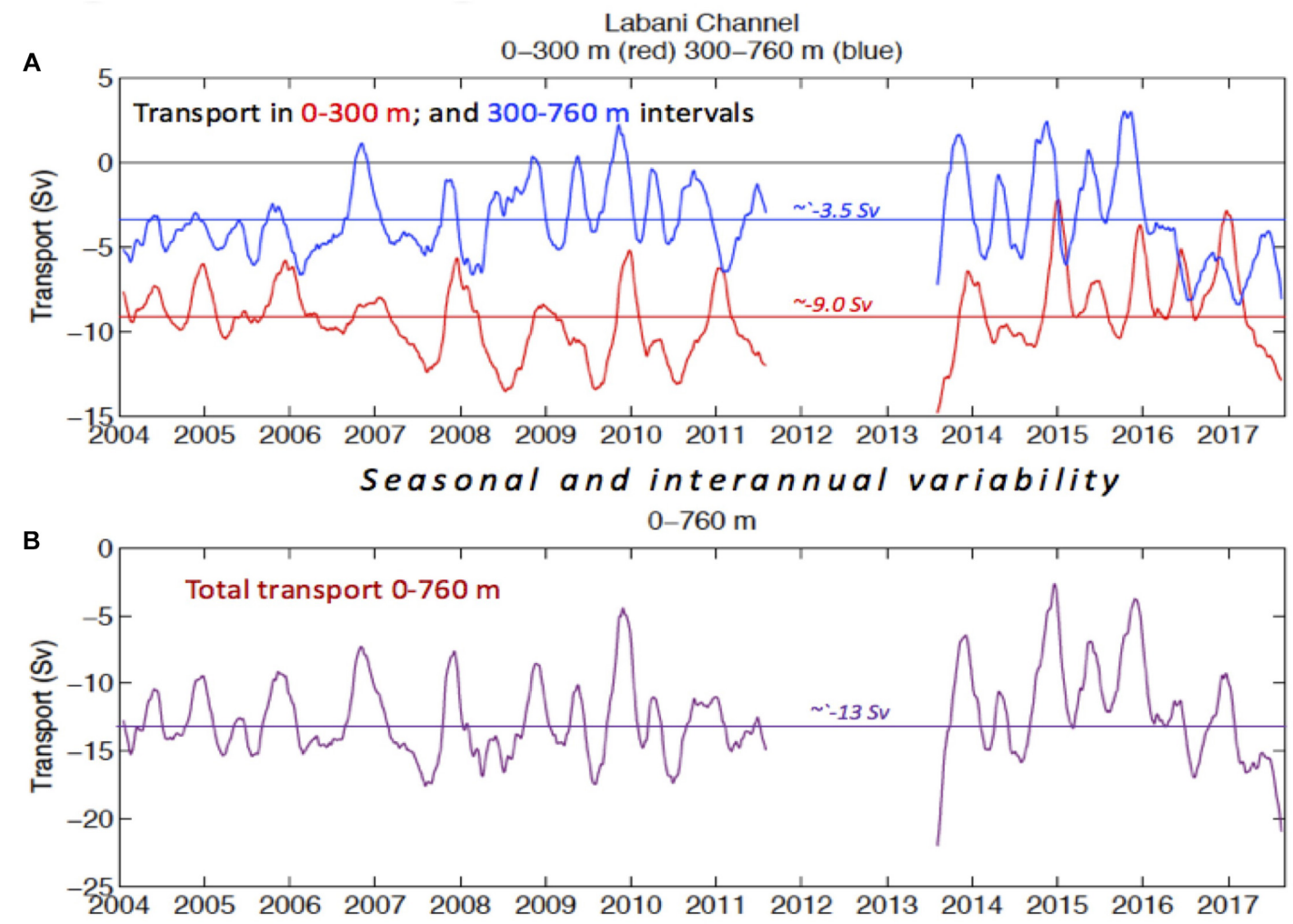

FIGURE 4 | (A) Volume transport in Sv (Sv, Sverdrup $=10^{6} \mathrm{~m}^{3} / \mathrm{sec}$ ) for the 0-300 $\mathrm{m}$ interval (red) and 300-760 $\mathrm{m}$ interval (blue) and (B) the total transport 0-760 $\mathrm{m}$ (purple). Negative flow is southward toward the Indian Ocean (Figure from Gordon et al., 2019).

Pacific Mindanao Current and the South Pacific New Guinea Coastal Current/Undercurrent system. These two low latitude western boundary currents collide to generate the westward flowing ITF, and the Mindanao and Halmahera retroflections that feed into the eastward flowing North Equatorial Countercurrent, as well as feeding into the Equatorial Undercurrent at depth. The retroflections and the presence of eddies at the Pacific entrance induce hysteresis effects and non-linear bifurcations that are thought to impact the transport, water properties, thermocline and sea level variability within the Indonesian seas (Kuehl and Sheremet, 2009; Yuan and Wang, 2011; Wang and Yuan, 2012, 2014).

The ITF variability in the eastern passages is poorly understood. The upper level transport through Lifamatola Passage and the other northeastern passages was not fully resolved during INSTANT. Only the deep part of Lifamatola Passage was monitored, with about $2.5 \mathrm{~Sv}$ found to enter the Indonesian seas below $1250 \mathrm{~m}$ (van Aken et al., 2009). However, since INSTANT, moorings have been deployed within the inflow pathways over the Sangihe Ridge, the Muluku Channel and the Halmahera Strait (Figure 1).

The upper $300 \mathrm{~m}$ Maluku Channel transport measured from December 2012 through November 2016 has a mean transport of $1.04-1.31$ Sv northward (Figure 5), although there is significant intraseasonal-to-interannual variability of over $14 \mathrm{~Sv}$ (Yuan et al., 2018). In particular, a southward change of over $3.5 \mathrm{~Sv}$ occurred in the spring of 2014. A high-resolution numerical simulation suggests that the variations of the Maluku Channel currents are associated with the shifting of the Mindanao Current retroflection. The spring 2014 change was coincident with a choked state of the Mindanao Current at the entrance to the Indonesian seas, which is different from the more eastward climatological retroflection typical of boreal fall-winter. The shifting of the Mindanao Current elevated the sea level at the entrance of the Indonesian seas driving the anomalous transport through the Maluku Channel. The results suggest the importance of the western boundary current non-linearity in driving the transport variability of the ITF.

The transport through the eastern passage of Halmahera Strait is thought to be small but represents an injection of saltier South Pacific water that is important for water mass transformation in the Indonesian seas (Cresswell and Luick, 2001; KochLarrouy et al., 2007). The bathymetry of the Halmahera Sea is convoluted with numerous small basins and shallow sills confounding attempts to obtain meaningful transport estimates. Numerous attempts have been made to determine transport from single point moorings (Cresswell and Luick, 2001; Koch-Larrouy, personal communication; Yuan, personal communication) with estimates of the mean transport across the Halmahera Strait ranging from $-1.5 \mathrm{~Sv}$ (westward) from June 1993 to June 1994 (Cresswell and Luick, 2001) to -2.4 Sv from November 2015 to October 2017 (Yuan, personal communication). 


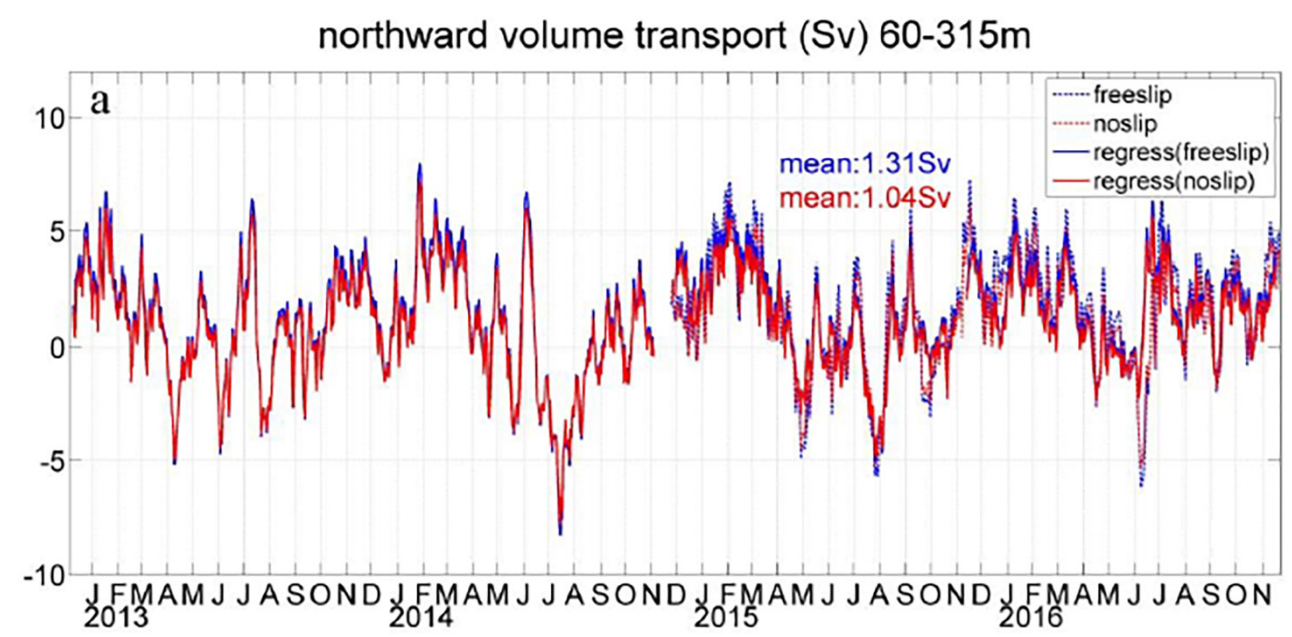

FIGURE 5 | Time series of the Maluku Channel transport (Sv) between 60 and 315 m from three ADCP moorings deployed during $2015-2016$ assuming free-slip (red dotted) and nonslip (blue dotted) conditions at the coasts, respectively. Solid blue and red curves are a regression model using the transport and the meridional velocity at the middle mooring that is then used to estimate the transports (from the middle mooring velocity) during 2012-2014 (Figure from Yuan et al., 2018).

\section{Western Pathways From the South China Sea}

The western route of ITF pathways via the Karimata Strait plays an important role in controlling the freshwater flux from the SCS into the Indonesian seas, impacting the ITF stratification (Tozuka et al., 2007, 2009; Susanto et al., 2010, 2013; Wang et al., 2019; Wei et al., 2019). In the main, the variability of the ITF transport is out-of-phase with the SCS Throughflow (Liu et al., 2006) that is well explained by the Island Rule theory (Qu et al., 2005; Wang et al., 2006). However, the SCS inflow contribution can vary from tidal to interannual time scales (Fang et al., 2010; Susanto et al., 2013; Wei et al., 2015). The inflow is influenced by seasonal reversal monsoon winds with stronger southward flow toward the Java Sea $(-2.7 \pm 1.1 \mathrm{~Sv})$ during the boreal winter monsoon and lesser flow toward the SCS (1.2 $\pm 0.6 \mathrm{~Sv})$ during the boreal summer monsoon (Fang et al., 2005, 2010; Susanto et al., 2010, 2013; Wang et al., 2019; Wei et al., 2019).

The Sunda Strait flow is northward toward the Java Sea during boreal winter monsoon $(0.24 \pm 0.1 \mathrm{~Sv})$ and southward $(-0.83 \pm 0.2 \mathrm{~Sv})$ toward the Indian Ocean during the boreal summer monsoon (Susanto et al., 2016). The Sunda Strait is the first gap of the pathway for coastally trapped Kelvin waves from the equatorial Indian Ocean. Intraseasonal inflows associated with Kelvin waves observed in Sunda Strait (Li S. et al., 2017) affected chlorophyll-a concentrations: higher levels were observed during outflow to the Indian Ocean and lower levels during inflow to the Java Sea (Xu et al., 2018). Thus, although the SCS inflow via the Karimata and Sunda Straits is smaller than the Makassar Strait inflow, both streams have a significant impact on the ITF stratification, freshwater flux and ecosystems within the Java Sea.

\section{Outflow Passages}

INSTANT found a total mean ITF transport from 2004 to 2006 of -15 Sv toward the Indian Ocean through the three major outflow passage comprised of -2.6 Sv in Lombok Strait, -4.9 Sv in Ombai Strait and -7.5 Sv in Timor Passage (Sprintall et al., 2009). The combined transport in Timor Passage and Ombai Strait is $>80 \%$ of the full-depth ITF transport, although Lombok Strait transport most resembles the variability of the total transport. The vertical transport structure in both Timor Passage and Lombok Strait are primarily surface intensified, although both flows have a weak subsurface maximum at 50-60 m. The Ombai Strait transport profile features both a surface maximum and an equally strong subsurface maximum near $180 \mathrm{~m}$ depth. Due to its shallow sill, Lombok carries the warmest waters $\left(21.5^{\circ} \mathrm{C}\right)$, Timor the next warmest $\left(17.8^{\circ} \mathrm{C}\right)$, and Ombai the coldest $\left(15.2^{\circ} \mathrm{C}\right)$ because of the subsurface velocity maximum.

As for the inflow passages, variability in the outflow is found over all time scales. The ITF outflow is strongly influenced by the Asian-Australian Monsoon. During the transition between the monsoons the reversal of the wind forcing over the Indo-Pacific results in a large seasonal and semiannual variation in the outflow transport and hence also in the transport weighted temperature and heat flux (Sprintall et al., 2009) as well as the nutrient flux (Ayers et al., 2014). The intraseasonal MJO variability affects the evolution of seasonal signals through the propagation of upwelling and downwelling Kelvin waves from the Indian Ocean (Drushka et al., 2010).

The Australian Integrated Marine Observing System (IMOS) deployed moorings in the Ombai Strait and Timor Passage between 2011 and 2015. The Ombai mooring occupied the same location as the INSTANT southern mooring in Ombai, however, the moorings in Timor Passage were located at the eastern edge of the passage and the array extended across the broad continental shelf north of Australia. The moorings in the Timor Passage and over the continental shelf underlie an altimeter ground track. Comparison of the Ombai Strait interannual transport variability and its relationship to the winds is quite different between the INSTANT (2004-2006) and IMOS ITF period (2011-2015) (Figure 6). The 7-year time series shows that while some of the transport peaks align with the wind divergence (La Niña/negative IOD), others do not. In addition, the upper (0-150 m) and deeper 


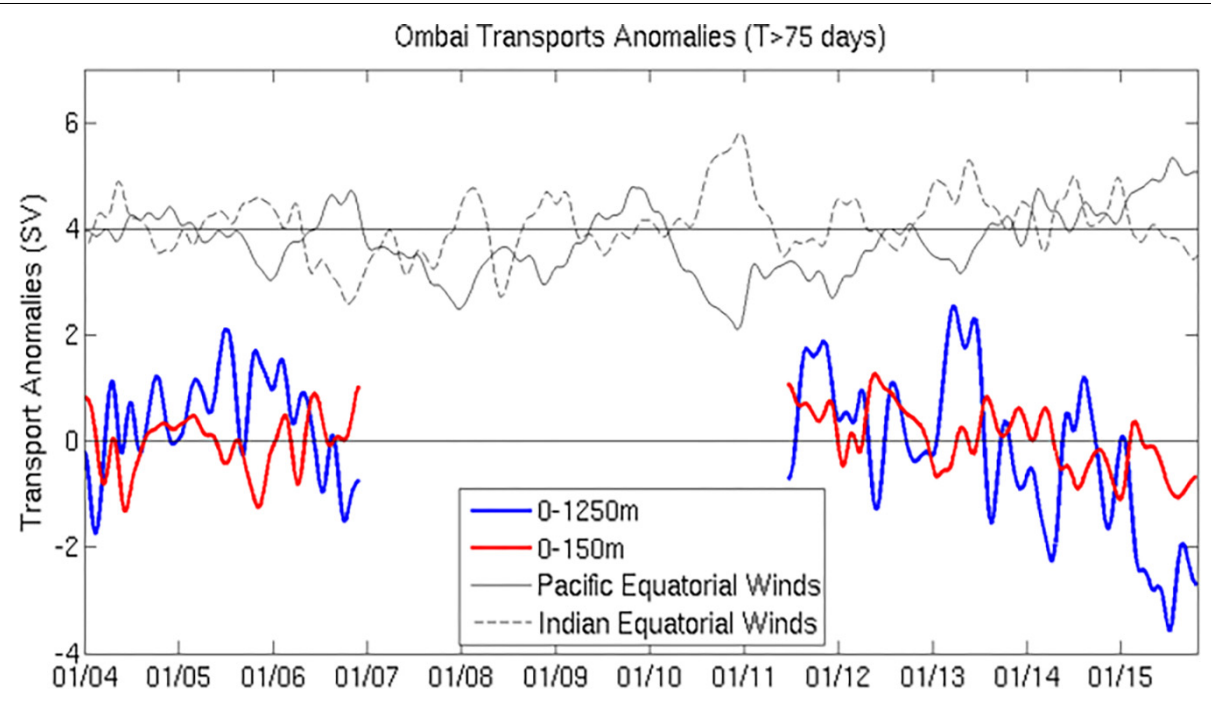

FIGURE 6 | Interannual ( $T$ > 75 days) time series of Ombai Strait transport anomalies from INSTANT (2004-2006) and IMOS ITF (2011-2015) for depth ranges 0-150 m (blue) and 0-1250 m (red). Also shown are the normalized zonal equatorial Pacific (solid) and Indian (dashed) Ocean winds from 2004 to 2015. Negative winds anomalies reflect stronger westerly trades winds over the equatorial region (Data from Wijffels et al., 2018).

$(0-1250 \mathrm{~m})$ transport anomalies are often out of phase. It is not yet clear what processes might drive these contrasting responses.

The net transport in the Timor Passage/Continental Shelf is smaller than found during the INSTANT program. The flow in the Timor passage at the IMOS mooring site is broader and more southern intensified than the narrower strait-centered jet measured by INSTANT at the western end of the Passage. While Ombai is strongly semi-annual at all depths, Timor Passage varies semi-annually only at depth (Figure 7), with annual variations dominating the stronger upper ocean component.

Using a proxy time series developed from INSTANT transport data in the outflow passages and altimetry data, Sprintall and Revelard (2014) found the partitioning of the total ITF transport through each of the major outflow passage varies according to the phase of the IOD or ENSO. In general, Pacific ENSO variability is strongest in Timor Passage, most likely through the influence of planetary waves transmitted from the Pacific along the Northwest Australian shelf pathway. Somewhat surprisingly, concurrent El Niño and positive IOD episodes consistently show contradictory results from those composites constructed for purely El Niño episodes, particularly in Lombok and Ombai Straits, but also at depth in Timor Passage. This suggests that Indian Ocean dynamics likely win out over Pacific Ocean dynamics in gating the transport through the outflow passages during concurrent ENSO and IOD events.

\section{The ITF in the South-Eastern Indian Ocean}

One of the longest running transport measurements in the Indo-Pacific region comes from a frequently repeated XBT section between Western Australia and Java - the IX1 line. This remarkable data set enables a monthly ocean geostrophic estimate of the upper ITF $(0-700 \mathrm{~m})$ to be made extending back 35 years since 1983 .
On interannual and longer time scales, remotely driven low frequency Pacific wind energy penetrates into the Indonesian seas and southward along the Western Australian coast (Pariwono, 1986; Wijffels and Meyers, 2004; McClean et al., 2005) and modulates both sea level and thermocline depth with the ENSO variability (Clarke and Liu, 1994). Wind-driven planetary long waves excited along the equatorial and coastal wave guides in the Indian Ocean also play a role in modulating the interocean exchange on intraseasonal through to interannual timescales. Wijffels and Meyers (2004) showed that about $60-90 \%$ of sea level variability and $70 \%$ of thermocline temperature variability within the Indonesian seas and geostrophic transport along the IX1 section can be understood in terms of free Kelvin and Rossby waves.

The multi-decadal IX1 time series has formed the observational basis of many recent analyses probing longterm changes in the Indo-Pacific circulation system. Interannual and multi-year variations of the ITF volume and heat transport may provide feedbacks to the climate variability in the IndoPacific. For example, based on IX1 XBT data analysis, the often co-occurring positive IOD (negative IOD) with El Niño (La Niña) was found to actually counter the direct ENSO effect during the developing phase of ENSO, resulting in a delayed ITF transport response to ENSO variability (Figure 8A; Liu et al., 2015; Feng et al., 2018). After the 2015/2016 El Niño, there was an unprecedented reduction of the ITF volume and heat transport, which is linked to a documented intensified warming and associated rising sea levels in the Indian Ocean over the last decade (Han et al., 2014). This may partly explain the weak and short lived La Niña conditions in 2016/2017 (Mayer et al., 2018).

The ITF outflow into the south-eastern Indian Ocean is also influenced by upwelling along the coast south of Java that occurs seasonally and is strengthened interannually as part of the IOD. 


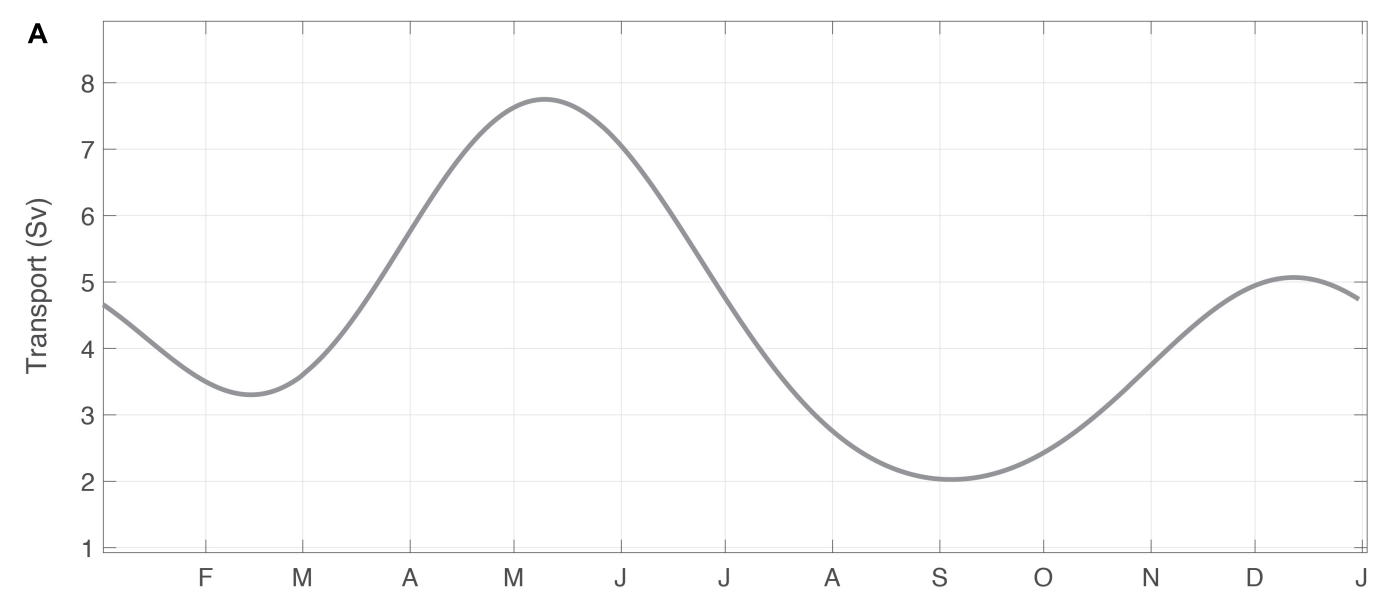

B

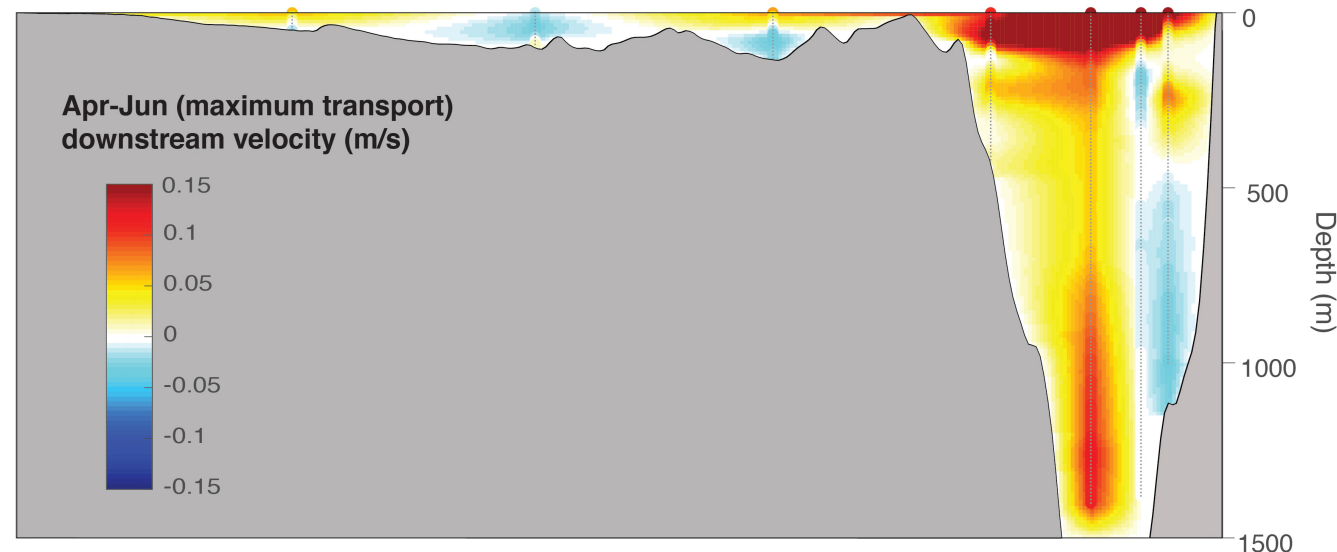

C

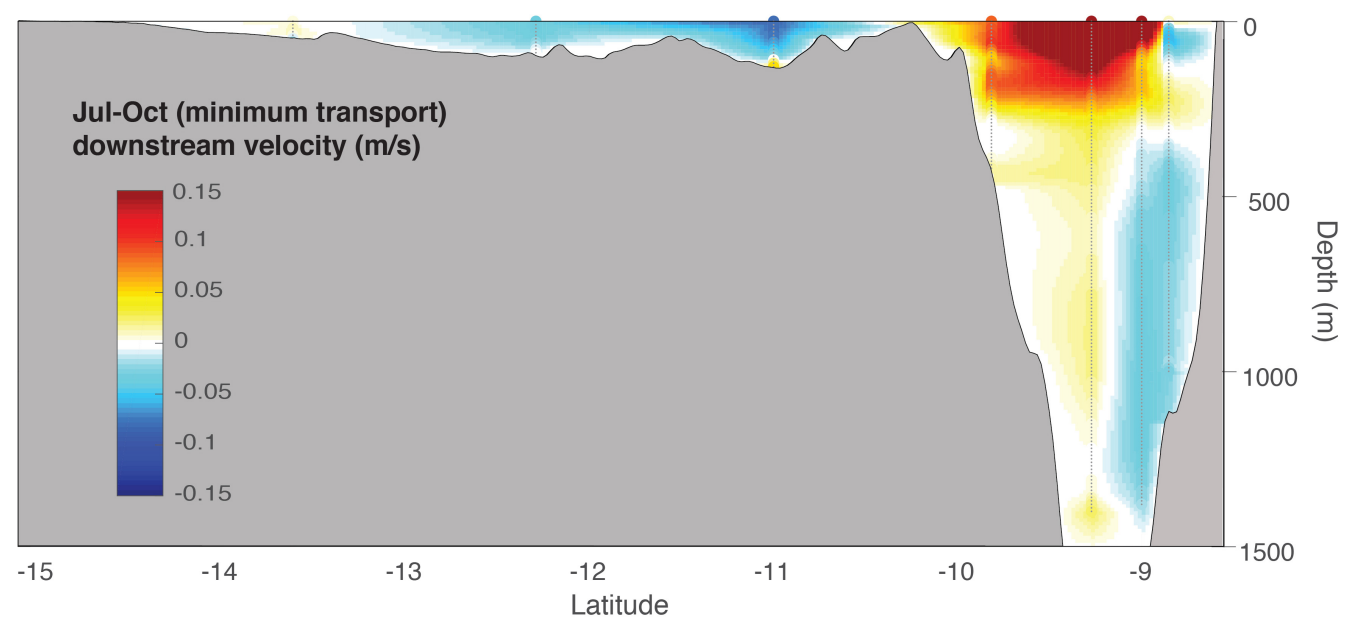

FIGURE 7 | Timor Passage and extension to northern Australian continental shelf IMOS moorings (2011-2015) (A) seasonal transport (Sv), mean velocity (m/s) section for (B) April-June and (C) July-October. April-June corresponds to maximum net transport and July-October to minimum net transport. Vertical lines indicate the position of the moorings.

The positive IOD can lift the thermocline depth off the SumatraJava coast in response to the enhanced upwelling (Feng and Meyers, 2003), and thus can induce a stronger ITF transport. Negative IOD would induce a weakened ITF transport anomaly. Together the upwelling and the ITF water supply the South
Equatorial Current (SEC) within the Indian Ocean (Wyrtki, 1962; $\mathrm{Qu}$ and Meyers, 2005). Indeed, the ITF/SEC mass transport could also be a trigger for the upwelling south of Java on both seasonal (Purba, 2007; Valsala et al., 2011; Kuswardani and Qiao, 2014) and IOD time scales (Delman et al., 2016; Delman et al., 2018). 


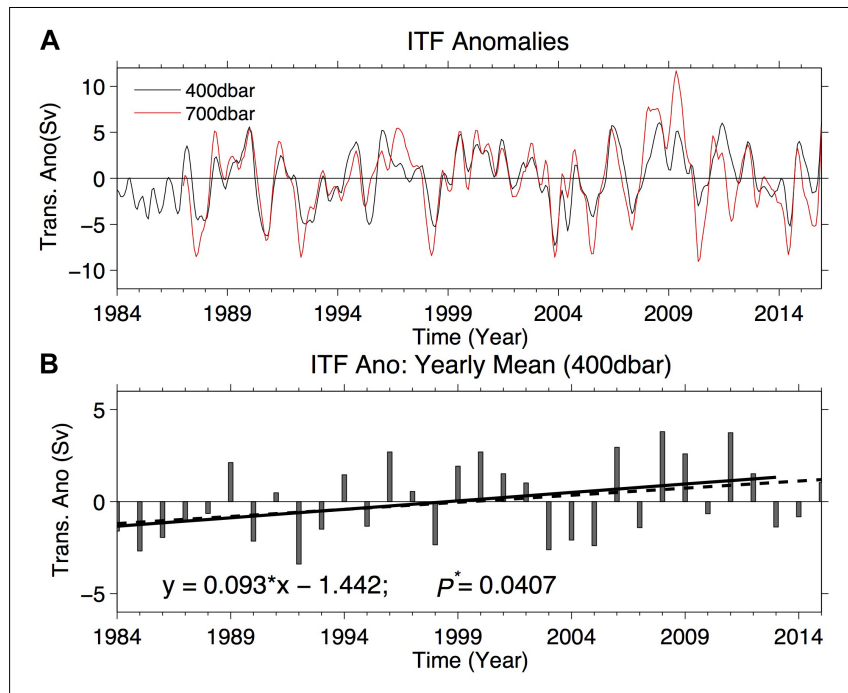

FIGURE 8 | The ITF geostrophic transport anomalies estimated from IX1 XBT data in the southeast Indian Ocean. (A) A monthly time series of the ITF transport anomalies estimated by IX1 XBT temperature records and monthly T-S relationship with reference depths of $400 \mathrm{~m}$ (black line) and $700 \mathrm{~m}$ (red line) from January 1984 to December 2015. Negative is toward the Indian Ocean (i.e., stronger ITF). (B) Annual mean ITF transport anomalies with a reference depth of $400 \mathrm{db}$ (bars) and their linear trends (lines) during 1984-2013 and during 1984-2015 (Figure from Feng et al., 2018. Permission obtained from author).

\section{Intraseasonal Variability Over the Maritime Continent}

Despite substantial recent progress over the past decade toward understanding the generation mechanism of the MJO in the Indian Ocean (e.g., Yoneyama et al., 2013; Moum et al., 2014; Pujiana et al., 2018), the MJO dynamics are still not fully understood, particularly those controlling the MJO behavior over the Indonesian seas. The mountainous Sumatra island, the westernmost island of the Indonesian archipelago, appears to exert a blocking effect on the eastward propagation of the MJO (Inness and Slingo, 2006). Weakened activities of the MJO over the Indonesian maritime continent have been attributed to competing interactions between diurnal precipitation over the Indonesian islands and the larger-scale MJO convective system (Peatman et al., 2014; Baranowski et al., 2016; Hagos et al., 2016). While land-air interactions have been suggested as the main mechanism responsible for the eastward propagation of the $\mathrm{MJO}$ over the maritime continent, the roles of air-sea interactions have been less explored. Improving our understanding on the underlying processes attributed to the $\mathrm{MJO}$ propagation, specifically the air-sea-land response to MJO forcing that is unique to the maritime continent, is critical because most rainfall within the Indonesian region is associated with MJO events. Understanding the variability on this time scale has received much attention since OO'09 as it is a principal focus of the YMC to be undertaken in 2018-2020.

Over the broader Indo-Pacific region, MJO-driven heat fluxes govern the heat content variability within the oceanic mixed layer (Drushka et al., 2012). Within the Indonesian seas, the
MJO surface heat fluxes account for a significant fraction of intraseasonal SST variances, with the strongest imprint observed in the Banda and Timor Seas (Napitu et al., 2015). Intraseasonal SST response to the MJO exhibits seasonal variation (strong during December-February and weak during June-August) and is dependent upon thickness of the surface mixed layer (Napitu et al., 2015). In addition, intraseasonal SST variance in the Banda and Timor Seas is also sensitive to thermocline depth. Deep thermoclines during December-February and La Niña (Gordon and Susanto, 2001) may decouple the surface mixed layer from the thermocline, making conditions more favorable for surface fluxes to regulate the rate of change of the mixed layer heat content. Shallow thermoclines during June-August and El Niño may intensify heat transfer between the surface mixed layer and the thermocline, elevating the role of ocean processes to govern the mixed layer heat content. Contributions from other oceanic processes that may govern SST response to the MJO, such as turbulent mixing, remain largely unknown.

The Indonesian seas not only respond to the MJO but may influence the evolution of the MJO while it traverses over the maritime continent. Only about $60 \%$ of the MJO events from the Indian Ocean appear to propagate over the maritime continent into the western Pacific (Napitu, 2017). Increased moisture content in the atmospheric boundary layer over the maritime continent, due to the warmer SST in the Indonesian seas, likely plays an important role in determining the MJO eastward propagation over the maritime continent to the western Pacific. Locally increased low-level specific humidity could strengthen the zonal gradient of moist static energy between the Indian Ocean and the Pacific Ocean, a key condition allowing MJO propagation over the maritime continent. An increased diurnal cycle amplitude explained the warmer SST observed during the suppressed phase of the MJO (Napitu, 2017). On interannual time scales, eastward propagation of MJO events occur more frequently during La Niña years than during El Niño years. The thermocline tends to be deeper during La Niña, thus inhibiting access of the cooler waters that would reduce SST and attenuate the MJO event.

\section{Decadal and Longer Time Scale Changes}

Because there is a lack of decadal modes of climate variability in the Indian Ocean (Han et al., 2014), decadal variations of the ITF transport are mainly associated with the decadal climate modes in the tropical Pacific, such as the Pacific Decadal Oscillation (PDO; Zhuang et al., 2013). On decadal and longer time scales, the circulation in the western equatorial Pacific Ocean is subject to the influence of the PDO that strengthens (weakens) the tropical Pacific trade winds during negative (positive) phases. The PDO is predictable if the meridional transport of the tropical gyre is used as a precursor (Zhou et al., 2018). The PDO pattern is believed to relay the corresponding anomalies into the marginal seas of the western Pacific Ocean, including the Indonesian seas, via westward propagating baroclinic Rossby waves (Lee and McPhaden, 2008; Trenary and Han, 2013; Dong and McPhaden, 2016). The changes ultimately impact the south Indian Ocean subsurface temperature and heat content variations (Ummenhofer et al., 2017; Zhou et al., 2017). 
Decadal modification of the Indo-Pacific atmospheric Walker Circulation (Vecchi et al., 2006; England et al., 2014) has directly influenced the strength of the ITF (Alory et al., 2007; Lee and McPhaden, 2008; Feng et al., 2011; Merrifield and Maltrud, 2011; Sprintall and Revelard, 2014; Hu et al., 2015; Liu et al., 2015; Mayer et al., 2018), as well as the heat (Alory et al., 2007; Schwarzkopf and Böning, 2011; Lee et al., 2015; Liu et al., 2015; Nieves et al., 2015) and freshwater (Phillips et al., 2005; VargasHernandez et al., 2015; Du et al., 2015; Hu and Sprintall, 2016, 2017) that has been redistributed from the neighboring Pacific through the Indonesian archipelago into the Indian Ocean.

Our first inkling that the PDO phases might impact ITF variability came when observational studies supported by model experiments found that the PDO-related climatic shift of 1976/77, associated with weakening of the easterly trade winds, led to shoaling thermocline anomalies in the western Pacific causing a decrease of the ITF into the Indian Ocean (Vecchi et al., 2006; Alory et al., 2007; Wainwright et al., 2008). Temperature records along IX1 after the mid-1970s to 1990s compared with historical observations from the 1950s to 1960s showed subsurface cooling anomalies corresponding to a weakened ITF geostrophic transport compared with the earlier decades (Alory et al., 2007; Wainwright et al., 2008; Liu et al., 2010). The response was similar to that which occurs during ENSO induced wind shifts (Wijffels and Meyers, 2004).

During the 2000s, the PDO transitioned toward its negative (La Niña like) phase with enhanced Pacific trade winds (Kosaka and Xie, 2013; England et al., 2014) that caused a dramatic heat increase in the Indian Ocean via the ITF, especially in the main thermocline $(100-350 \mathrm{~m})$ and in the southeast Indian Ocean (Feng et al., 2011; Lee et al., 2015; Nieves et al., 2015; Dong and McPhaden, 2016; Liu et al., 2016; Cheng et al., 2017; Li Y. et al., 2017; Ummenhofer et al., 2017; Zhou et al., 2017). The strengthening trend of the ITF geostrophic transport across the IX1 XBT section is about $1 \mathrm{~Sv}$ every 10 years over the period 1984-2013 (Liu et al., 2015; Feng et al., 2018), although the trend may start to reverse due to the influence of the most recent El Niño events in 2014-2016 (Figure 8). This is consistent with a multi-decadal timeseries of 0-300 m Makassar Throughflow, reconstructed from NCEP reanalysis wind data and Makassar Strait transport, suggesting that the Makassar throughflow decreased from 1948 to 1995, increased after 1995, and decreased after 2013 (Li et al., 2018). Over longer time scales, a coral record suggested that the PDO significantly impacted the Indo-Pacific coupling (Crueger et al., 2009), influencing the ITF strength over the past 200 years that consequently played an important role in modulating the warming rate in the IndoPacific basins (Hennekam et al., 2018).

Heat redistribution in the upper layer through the ITF has also been closely tied to the surface warming hiatus from the mid 1990s through mid-2000s, leading to heat content changes in the Pacific and Indian Oceans. During the hiatus period, the enhanced ITF heat transport compensated the enhanced heat uptake by the Pacific Ocean (Lee et al., 2015; Nieves et al., 2015; Dong and McPhaden, 2016; Liu et al., 2016) and led to an accelerated warming in the south Indian Ocean. These changes are evident in the observations, model simulations and reanalysis products from the Indian Ocean. At present there are relatively few direct time series records available in the Indonesian seas that might be used to directly corroborate the link to corresponding changes in the ITF profile.

In addition to sea temperature changes, decadal sea surface salinity trends are also evident in the Indo-Pacific region ( $\mathrm{Du}$ et al., 2015), and salinity variability is known to play a role in regulating the ITF transport (Gordon et al., 2003; Andersson and Stigebrandt, 2005; Feng et al., 2015; Hu and Sprintall, 2016, 2017; Newton, 2018). The advection of freshwater from the Indonesian seas results in an average freshening of $0.2 \mathrm{psu}$ in the IndoAustralian basin during strong La Niña events (Phillips et al., 2005; Zhang et al., 2016). Andersson and Stigebrandt (2005) proposed that buoyancy forcing associated with freshwater gain and vertical mixing in the northern and equatorial western Pacific is an important factor to determine the pressure gradient between the ocean basins that regulates the long-term ITF transport from the Pacific to the Indian Ocean (Wyrtki, 1987). Hu and Sprintall (2016) found that about $36 \%$ of the interannual ITF transport is attributable to the halosteric contribution. Strengthening of the ITF transport in the 2000s, and the significant increase in freshwater input over the Indonesian seas, contributed to a subsequent warming and freshening of the eastern Indian Ocean (Hu and Sprintall, 2017).

In the future, climate models consistently project a substantial decrease in the ITF transport in response to enhanced greenhouse warming. A multi-model mean reduction of $3.4 \mathrm{~Sv}$ is predicted by the end of the century, corresponding to $>20 \%$ of the multimodel mean ITF transport of 15 Sv (Hu et al., 2015; Sen Gupta et al., 2016). The declining trend of the ITF in the future climate scenarios appears to be associated with a weakening trend of deep water formation in the Southern Ocean and a slowdown of upwelling in the deep Pacific Ocean (Sen Gupta et al., 2016). Using an eddy-rich (10 km) downscaled near-global ocean model captures a similar weakening of the ITF that is mainly attributed to the slowdown of the deep upwelling in the Pacific basin in the future (Feng et al., 2017). This implies that the deep contribution to the ITF will be weaker in a future warm climate, influenced also by the stronger near-surface water column stratification and a reduction of deep water formation rate.

\section{MIXING OBSERVATIONS AND TIDAL MODELING: SIGNIFICANCE TO WATER MASS FORMATION AND CLIMATE}

\section{Introduction}

Perhaps one of the most consequential outcomes of recent research within the Indonesian seas is a better appreciation of the role of elevated tidal mixing in both transforming the incoming Pacific water masses and in modifying regional SST and global climate. In the Indonesian seas, large tidal currents interact with the rough topography and create strong internal waves at the tidal frequency, called internal tides that eventually propagate and dissipate. Somewhat uniquely, the Indonesian archipelago is the only region in the global ocean with strong internal tide generation in a semi-enclosed area. As a result, all of the internal (or baroclinic) tidal energy remains trapped locally inside the 
archipelago and is available for dissipation. Thus, the archipelago is one of the world's largest internal tide generation sites (10\% of the global value) (Nagai and Hibiya, 2015).

As a result of internal tidal mixing, water masses are transformed when entering the archipelago (Ffield and Gordon, 1996; Hautala et al., 2001; Koch-Larrouy et al., 2007). Ffield and Gordon (1992) estimated from observations that vertical diffusivities of $10^{-4} \mathrm{~m}^{2} / \mathrm{s}$ are needed to explain the transformation. Over this past decade, there has been a concerted internationally collaborative effort to better understand where, at what depths and under what conditions strong vertical diffusivities might occur in the Indonesian seas. It has been shown that it is critical for models to parameterize or include this mixing in order to get the air-sea coupling important to climate and regional ocean productivity correct (e.g., Jochum and Potemra, 2008; Koch-Larrouy et al., 2010). Yet large uncertainties remain in our current understanding of processes associated with internal tide generation and dissipation.

\section{Tidal Mixing Signatures From SST}

Two decades ago Ffield and Gordon (1996) provided some of the first direct evidence of strong tidal mixing in the Indonesian seas. During the fortnightly spring-neap cycle, stronger tidal currents occur during spring tides that enhance mixing such that the colder subsurface water lowers the observed SST. Ffield and Gordon (1996), using limited field observations, suggested that much of the stronger tidal mixing occurs in the internal Banda Sea. Yet, subsequent limited microstructure measurements in the central Banda Sea (Alford et al., 1999) found no fortnightly signal in kinetic energy dissipation, and low diapycnal diffusivity. Ray and Susanto (2016) recently revisited the Ffield and Gordon (1996) premise, albeit using higher-spatial and temporal resolution remotely sensed SST data and concluded that the strongest fortnightly SST patterns are mostly localized to narrow straits, channels and sills, especially along the exit passages of the ITF (Figure 9) where strong internal waves have been observed (Susanto et al., 2005; Aiki et al., 2011; Matthews et al., 2011) and along the southern boundary of the Sulu Sea (Tessler et al., 2012). Numerical models predict that tidal currents are large in the same regions and tidally induced mixing is anticipated (Figure 9; Koch-Larrouy et al., 2007; Nagai and Hibiya, 2015).

\section{Mixing Estimates From Direct Measurements}

The Indonesian Mixing program (INDOMIX 2010) was designed to directly quantify the very strong mixing that transforms Pacific waters into the isohaline Indonesian waters in the Indonesian archipelago (Koch-Larrouy et al., 2015). Turbulent dissipation rates and associated mixing were estimated and analyzed combining physical and geochemical in-situ observations: (1) direct measurements of the dissipation using a Velocity Measuring Profiler (VMP) microstructure system, (2) use of density-based fine-scale methods applied to CTD and XCTD data, and (3) study of the vertical distribution of natural radionuclides (radium isotopes and actinium-227). Data were collected at contrasting stations within the Indonesian archipelago: above energetic straits or in relatively quiescent large basins. Both the fine-scale and micro-scale methods identified very strong energy dissipation levels above the straits, ranging between $\left[10^{-7}, 10^{-4}\right] \mathrm{W} \mathrm{kg}{ }^{-1}$. Enhanced mixing is found to occur preferentially above rough topography and lower mixing occurs further away from the generation sites, for example at the center of the Halmahera Sea $\left(\left[10^{-9}, 10^{-8}\right] \mathrm{W} \mathrm{kg}^{-1}\right)$ and within the Banda Sea $\left(\left[10^{-11}, 10^{-10}\right] \mathrm{W} \mathrm{kg}^{-1}\right)$. Vertical eddy diffusivities ranged between $5.10^{-4}$ and $5.10^{-1} \mathrm{~m}^{2} \mathrm{~s}^{-1}$, except
A

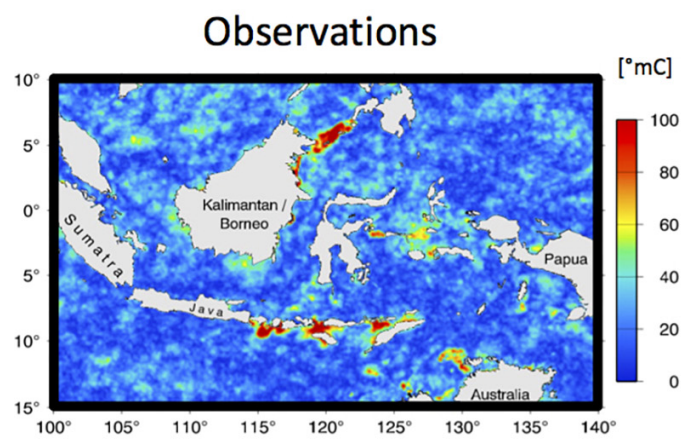

B

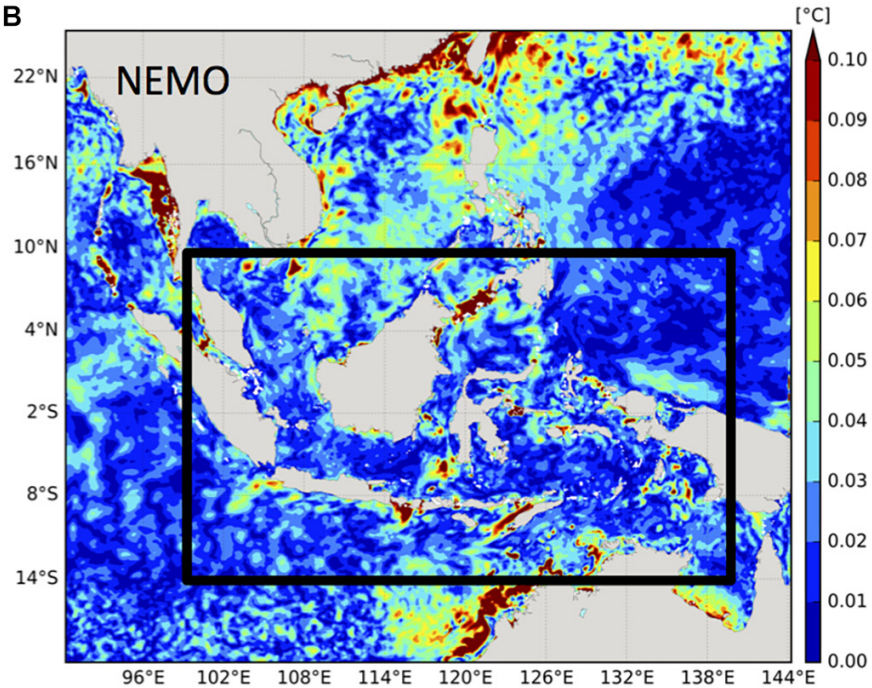

FIGURE 9 | Amplitude of the spring-neap (MSf) tidal component in sea surface temperature, extracted from (A) over 12 years of MUR-SST data (in ${ }^{\circ} \mathrm{mC}$ (Figure from Ray and Susanto, 2016) and from (B) the NEMO INDESO model (in ${ }^{\circ} \mathrm{C}$ ). High amplitude (red) indicates strong tidal mixing. (Figure from Nugroho et al., 2017. Permission obtained from Elsevier). 
in the Banda Sea where values are similar to that of the open ocean $\left(10^{-6} \mathrm{~m}^{2} \mathrm{~s}^{-1}\right)$. Surface mixing at the base of the mixed layer is very strong with values between $\left[10^{-4}, 10^{-3} \mathrm{~m}^{2} \mathrm{~s}^{-1}\right]$. In general, while the three methods broadly agreed, the finestructure method differed in the depth of mixing from the other methods and also detected a larger range in the dissipation between stations.

\section{The Challenges of Modeling Tidal Mixing in the Indonesian Seas}

Climate models need to account for the intensified ocean mixing to properly represent the mean state and variability of the tropical climate system (Koch-Larrouy et al., 2007, 2010; Sprintall et al., 2014). However, in order for models to account for this mixing several challenges need to be overcome. Internal tide scales cover from kilometers for their propagation to centimeters/millimeters for their dissipation. A model capable of simultaneously resolving these scales does not yet exist.

Koch-Larrouy et al. (2007) implemented a tidal mixing parameterization in the NEMO OGCM specifically for the Indonesian archipelago that produced the heterogeneous vertical diffusivities in good agreement with the INDOMIX observations (Koch-Larrouy et al., 2015). However, parameterization represents only a first step toward accounting for the mixing induced by the internal tides. In reality, the dissipation may not occur exclusively locally but rather some fraction could dissipate in the far field. Also, dissipation may vary in time following the cycling of the surface tides. Such limitations and the increase of model resolution encouraged scientists to force their models using explicit tidal forcing in the Indonesian seas (e.g., Robertson and Ffield, 2005; Kartadikaria et al., 2011; Castruccio et al., 2013; Nagai and Hibiya, 2015; Nugroho et al., 2017) with model resolutions between 5 and $10 \mathrm{~km}$.

Models that do not account for the additional mixing induced by the tides produce large biases in the water masses in the Indonesian region (Schiller et al., 1998; Schiller, 2004; KochLarrouy et al., 2007, 2008; Sasaki et al., 2018). The addition of explicit tidal forcing produces an intensified mixing that better reproduces the isohaline Indonesian water in the Banda Sea (Figure 10; see also Kartadikaria et al., 2011; Castruccio et al., 2013; Nugroho et al., 2017). However, quite surprisingly the model that includes the explicit tidal forcing (Nugroho et al., 2017) produces almost the same mixing as in the coarser resolution model that parameterizes the internal tides (KochLarrouy et al., 2007; Figure 10). This suggests that the processes involved in the dissipation of the internal tides are not being fully resolved. The question then is how is the model able to create mixing when no specific internal tides are active in the model? Is the spatial distribution of the tidal mixing in the model correct? Is mixing occurring at the correct rate over the evolutionary time span of the internal tides? To tackle this issue, we briefly discuss the advances and limitations of various models, that handle tidal mixing in various ways and are of various horizontal resolutions, over the life cycle of the internal tides in the Indonesian seas.

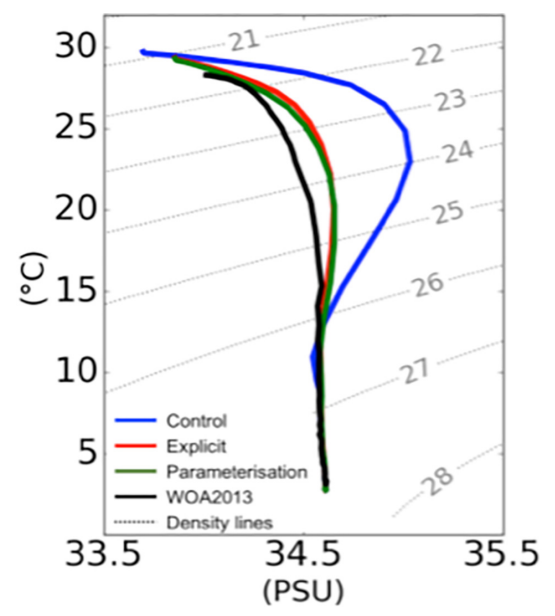

FIGURE 10 | Temperature-salinity diagram of averaged properties in the Banda Sea $\left(124.75^{\circ} \mathrm{E}-130.83^{\circ} \mathrm{E} ; 6.65^{\circ} \mathrm{S}-4.41^{\circ} \mathrm{S}\right)$ from the NEMO simulation that does not include tides (CTRL: blue line); the NEMO simulation that includes explicit tides (EXPL: red line); the NEMO simulation that parameterizes tides (PARAM; green line) and the WOA 2013 observed climatology (Figure from Nugroho et al., 2017. Permission obtained from Elsevier).

\section{Generation}

Model-based estimates give ranges of 85-110 GW of energy transfer to the internal tide within the Indonesian seas, about $10 \%$ of the total global generation (Nagai and Hibiya, 2015). Niwa and Hibiya (2011) show that using a $9 \mathrm{~km}\left(\sim 1 / 12^{\circ}\right)$ resolution, their model is able to generate only $75 \%$ of the internal tides. With a $4 \mathrm{~km}\left(\sim 1 / 36^{\circ}\right)$ resolution, the model generates $90 \%$ of the internal tides and explicitly solves the internal tides with some accuracy. Compared to the FES2014 global tidal model at $1 / 12^{\circ}$ resolution with 11 tidal components, NEMO reproduces $75 \%$ of the total estimated energy (Nugroho et al., 2017), whereas at $1 / 100^{\circ}$ resolution the MITgcm with only M2 reproduces $\sim 95 \%$ of the M2 estimate (Nagai and Hibiya, 2015). For these three models, generation sites are the strongest at the entrance eastern passages of Halmahera, Lifamatola, Sula and Buru straits, the Sangihe Island chain, the Sulu Strait and Dewakang sill in Makassar Strait (Figure 11). Strong internal tides are also produced within the exit passages of Ombai, Lombok, and Sumba Straits.

The baroclinic component of the tides extracted from the sea surface height of the NEMO (Nugroho et al., 2017) and HYCOM (Ansong et al., 2015), both at $1 / 12^{\circ}$ resolution, and the MITgcm (Nagai and Hibiya, 2015) at $1 / 100^{\circ}$ resolution compares well to altimetry data (Figure 12). Regional differences exist between the models, such as above Dewakang sill in Makassar Strait and in the Flores Sea, and the amplitude of the baroclinic tides in NEMO is weaker than HYCOM. Although HYCOM is more realistic, the amplitude of the tidal signature is still too strong compared to the observations. The MITgcm also gives too large sea surface height elevations (Nagai and Hibiya, 2015). Differences are likely due to the parameter choices between models, although it is not yet fully understood why these differences occur. 

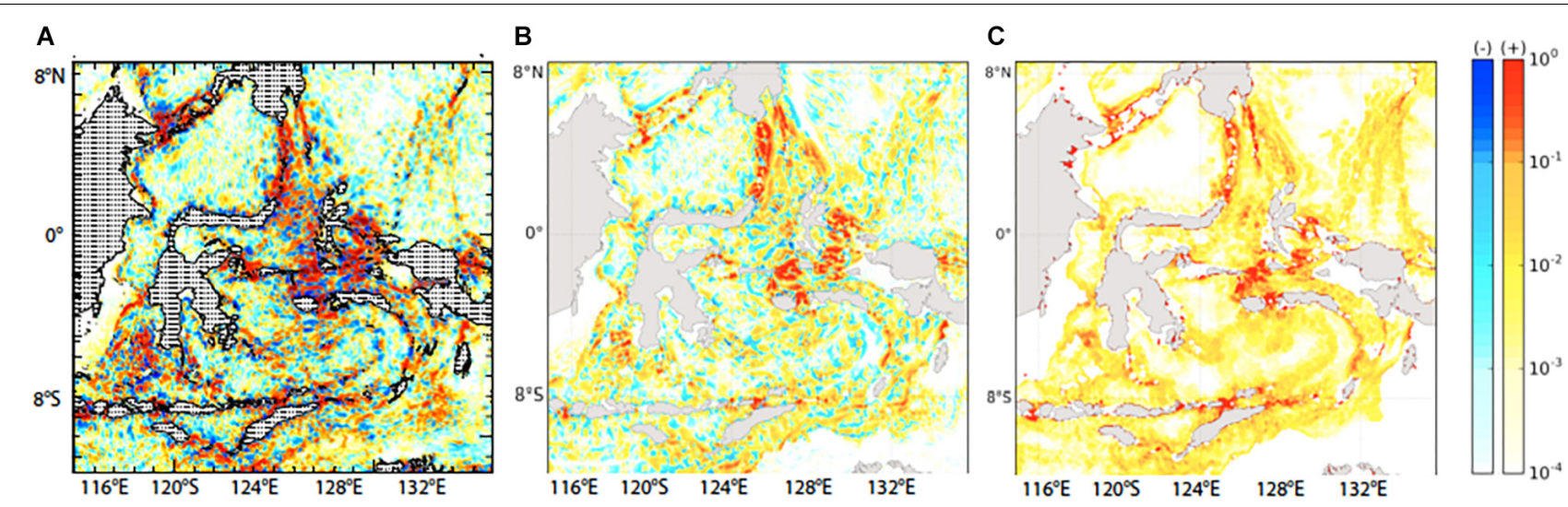

FIGURE 11 | Generation regions of internal tides, which correspond to the energy transfer from barotropic to baroclinic tides (Logarithmic scale, Wm ${ }^{-2}$ ), from (A) MITgcm (1/100), (Figure from Nagai and Hibiya, 2015), (B) INDESO NEMO and (C) FES2014 (Figure from Nugroho, 2017. Permission obtained from author). Red colors are likely generation areas whereas blue might be an artifact of the model and/or the numerical calculation due to possible non-linear interaction between the surface and internal tides.

\section{Propagation}

Once generated, part of these internal tides may propagate. But the fraction of the waves that dissipates locally or propagates further away to dissipate in the far field remains a big unknown within the Indonesian seas. The velocity for the four tidal components (M2, K1, S2, O1) in the NEMO $1 / 12^{\circ}(9 \mathrm{~km})$ model with explicit tidal forcing shows the clear propagation of mode 1 and 2 internal tides from the Sangihe Islands and Lifamatola Strait (Nugroho et al., 2017; Figure 13). Note that at this resolution, the model is only capable of resolving the mode 1 and mode 2 internal tides with length scales of $\sim 100$ and $\sim 50 \mathrm{~km}$, respectively (Nugroho, 2017). NEMO seems to produce larger baroclinic fluxes than the MITgcm (Figure 14). In Sulawesi, internal tides coming both from the Sangihe Ridge and Buru Straits interact and almost fill the entire sea, in quite good agreement with altimetry and SAR images (Nugroho et al., 2017). Strong propagation is also found from the Sula, Buru and Ombai Straits filling the western Banda Sea, while northern propagation from Lifamatola and Sumba Straits may act to transform Pacific water masses (Koch-Larrouy et al., 2007). Still, this comparison with altimetry is only qualitative, and more dedicated field studies are needed to validate the path and energy of the propagating tides.

\section{Dissipation}

Models can provide 3-dimensional maps of dissipation, to evaluate how much mixing is produced in the local vs. far field (Figure 14, color shading). However, many models do not have the resolution nor physically based parameterization to constrain this field. Both the NEMO $1 / 12^{\circ}$ (Nugroho et al., 2017) and the MITgcm $1 / 100^{\circ}$ (Nagai and Hibiya, 2015) find dissipation is stronger above generation sites and in the near field than further away. In NEMO most of the tidal energy is dissipated in the interior by horizontal momentum dissipation (Nugroho et al., 2017) while in reality one would expect dissipation through vertical processes. Only about $20 \%$ of the mixing remains for far field dissipation, and this seems to mainly occur in the
Banda Sea. Nagai and Hibiya (2015) found about $50-75 \%$ of the dissipation occurs locally near the straits and sills where the tides are generated, although they do not distinguish between vertical and horizontal dissipation processes. In both studies, there is a residual of an unphysical source of dissipation that may come from numerical dissipation [20\% in the MITgcm model of Nagai and Hibiya (2015) and 40\% in the NEMO model of Nugroho et al. (2017)].

The NEMO model and the INDOMIX data are surprisingly in good agreement in terms of tidal energy dissipation estimates within the straits (Nugroho et al., 2017). However, in regions further away from the generation sites where INDOMIX found no evidence of intensified mixing, the model produces too strong mixing. The bias comes from the lack of specific set up of internal tides in the model and a too strong baroclinic flux (e.g., Figure 14). Improving the modeled dissipation and validating the model energy fluxes is a theme of ongoing active research.

\section{Tidal Mixing Feedbacks to Climate and Biology}

The mixing induced by the simulated tides produces a significant SST cooling of $0.3-0.8^{\circ} \mathrm{C}$ in the areas of internal tide generation. Additional cooling occurs in models that include explicit tidal forcing due to the exchange of water mass properties (e.g., Malacca Strait) and bottom dissipation (e.g., over the Northwest Australian shelf). The simulated and observed cooling is stronger in austral winter when the thermocline is shallower (Kida and Wijffels, 2012; Nugroho et al., 2017). This cooling increases ocean heat uptake by $\sim 20 \mathrm{~W} \mathrm{~m}^{-2}$ and reduces the locally driven deep atmospheric convection and the associated rain activity by as much as 20\% (Jochum and Potemra, 2008; Koch-Larrouy et al., 2010; Sprintall et al., 2014). Tidal mixing within the Indonesian archipelago has also been shown to influence the discharge and recharge of upper-ocean heat content in the Indo-Pacific region (Koch-Larrouy et al., 2010). This in turn regulates the amplitude and variability of ENSO, the IOD and the MJO. Indeed, models 

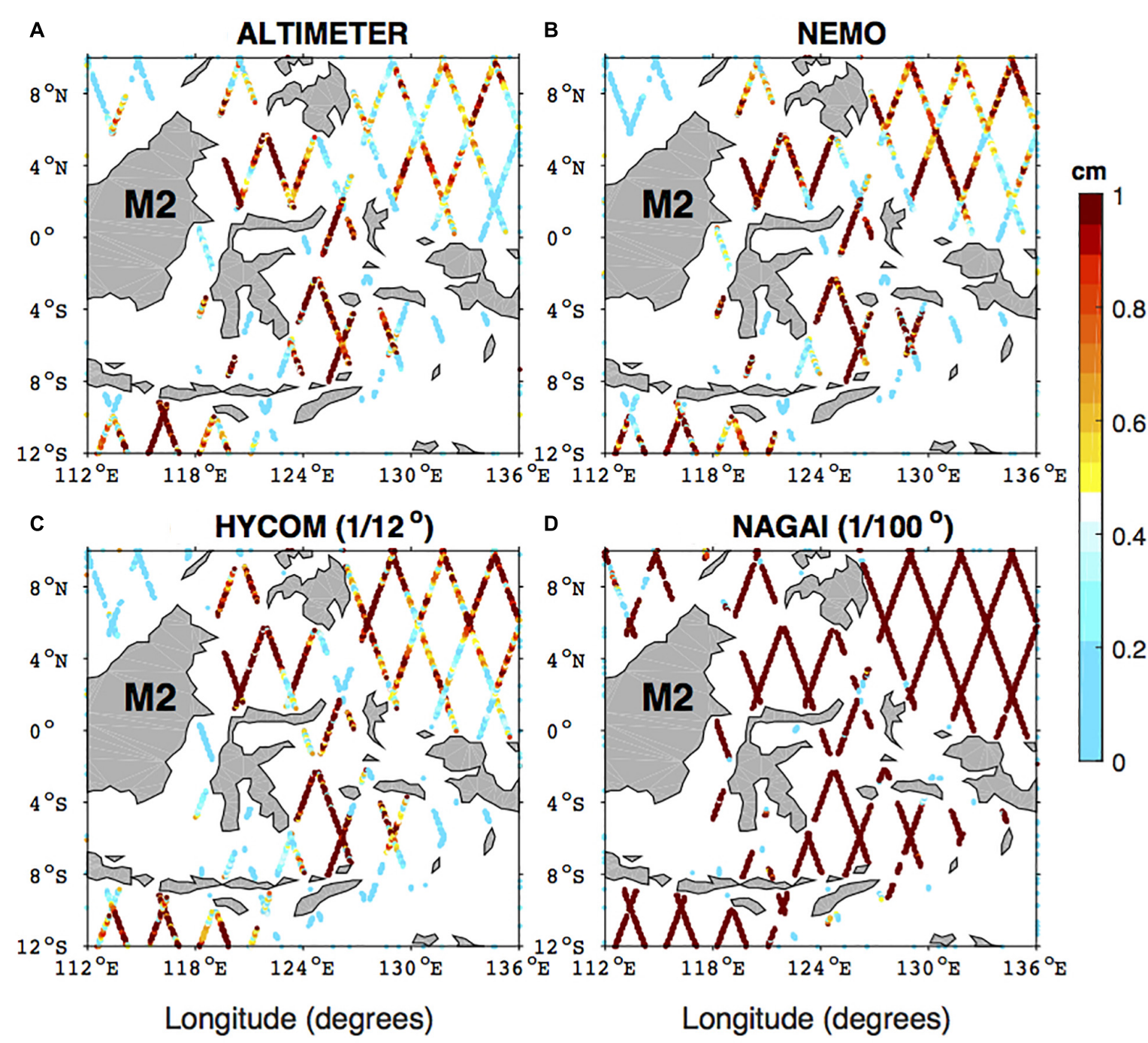

FIGURE 12 | The baroclinic tides (cm) from (A) along-track TOPEX/Poseidon and Jason satellite altimeter data (1992-2009) (B) the NEMO 1/12 ${ }^{\circ}$ INDESO model configuration (Nugroho et al., 2017) and (C) the HYCOM 1/12 ${ }^{\circ}$ model configuration (Ansong et al., 2015) and (D) the MITgcm (1/100 ${ }^{\circ}$, Nagai and Hibiya, 2015). Details of the approach used to extract baroclinic tides from the HYCOM output and along-track altimeter data are provided in Shriver et al. (2012). Model output are interpolated to the altimeter tracks. For models and altimeter output, spatial band-pass filtering along the altimeter tracks is used to extract the M2 internal tide signals with wavelengths in the 50-400 km range. Only locations with sea floor depth greater than $1500 \mathrm{~m}$ are plotted (Figure from Ansong et al., 2015).

that include tidal mixing have improved representation of ENSO, IOD and MJO patterns (Koch-Larrouy et al., 2010; Sprintall et al., 2014). However, in reality, the complexity of the atmospheric response to enhanced mixing remains poorly understood and is a topic of ongoing research.

The impact of mixing on biological activity has also not yet been fully studied, but it could be speculated that the vertical mixing would have a significant impact on phytoplankton blooms through the upwelling to the surface of nutrient-rich water. INDOMIX found that vertical mixing (directly measured by the VMP) is the dominant process transforming the nutrients (nitrate, silicate, phosphate) and the vertical distribution of oxygen measured in the Halmahera Sea. Very strong mixing is needed in this small sea where the residence time is quite rapid (2 days). As such, vertical mixing dominates over the biogeochemical processes in explaining the transformation of the vertical distribution of nutrients and oxygen from the Pacific to the Halmahera Sea. More concurrent physical and biogeochemical in-situ data are needed to corroborate this and determine whether this occurs in other regions of the maritime continent.

\section{PATHWAYS TOWARD AN ITF INTEGRATED OBSERVING ARRAY}

Long term monitoring of the ITF and the Indonesian seas remains both a logistical and technological challenge. The ITF 

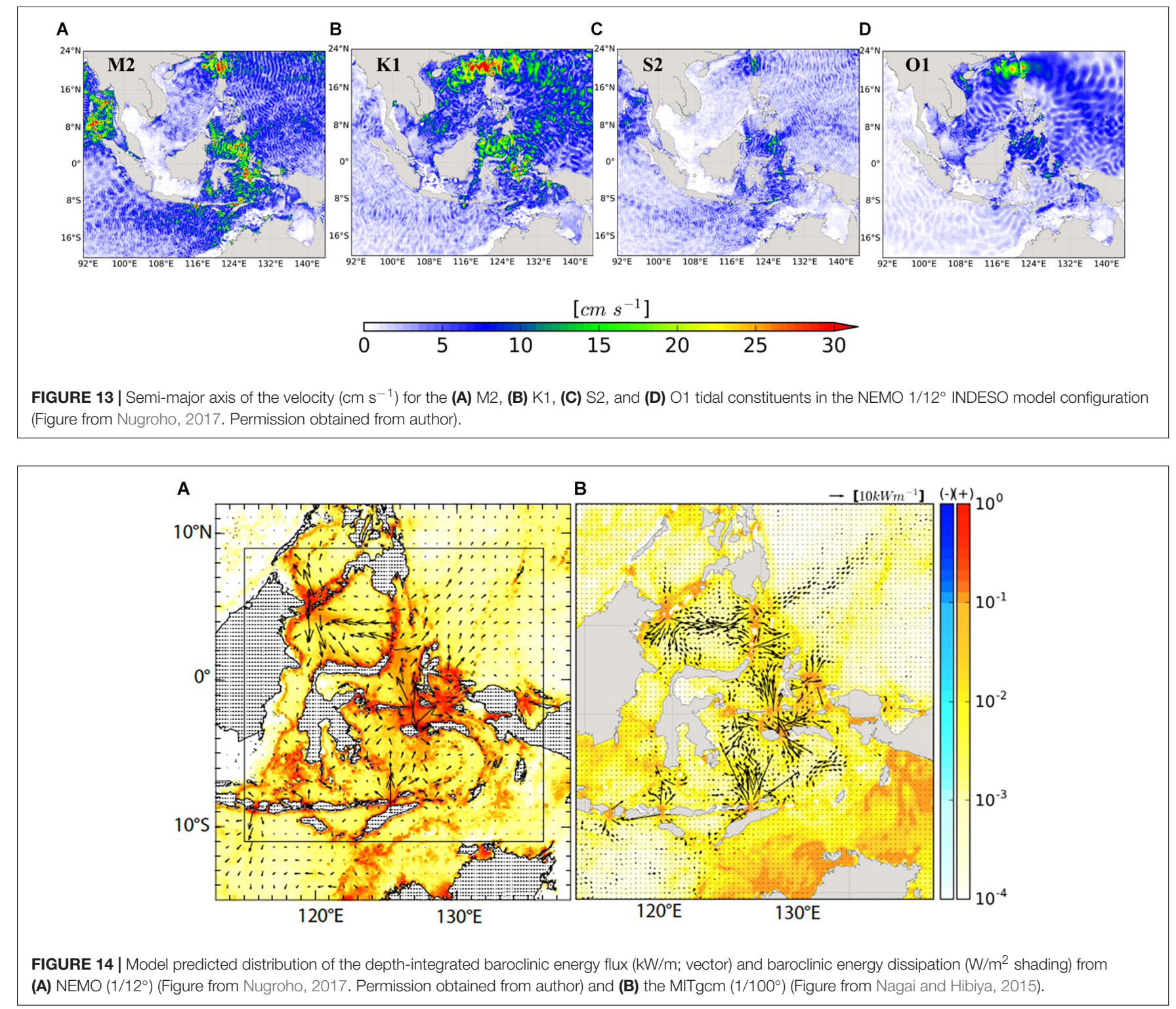

differs on time scales of interest from diurnal to decadal with phase differences from strait to strait. Clearly a multiplatform approach would offer the best strategy for developing an integrated array to measure the mass, heat and freshwater fluxes of the ITF. Here we break up the challenge of developing an observing array into several targets and possible approaches that use both existing platforms and emerging new technologies.

\section{ITF Volume and Climate Fluxes}

Prior to INSTANT, the main throughflow passages were monitored over different years and for varied lengths of time, making it impossible to assemble a simultaneous picture of the multiple corridors of the ITF that captured the inherent variability. INSTANT revealed the need for concurrent measurements in the major inflow and outflow passages in order to depict the evolving partitioning of transport through the major passages, and thus the full ITF. However, such an array is logistically difficult (e.g., ship-time requirements) and expensive to maintain. In addition there are a number of challenges faced by the various platforms that are used by a monitoring array for resolving the aspects of the ITF flow.

Moorings excel at providing a continuous time series of the velocity to the depths of the interocean exchange $(\sim 1250$ $\mathrm{m})$ in the narrow and tidally dynamic passageways of the ITF. Technological advances in moored instrumentation and floatation offers some optimism that a simplified sparse moored array could capture the key transport variability. Coverage of each of the major passages (Makassar, Lifamatola, Halmahera, Lombok, Ombai and Timor) is desirable. Measurements of the eastern inflow via the Halmahera Passage is particularly sparse, and more exploratory work is needed to better target longer term monitoring sites. Simplified velocity moorings comprising of 2-3 
long-ranging ADCPs with low-tilt floatation (to keep the ADCPs vertical) can be used to monitor the flow. The lack of a surface toroid to prevent detection has made it difficult for real-time transmission of the subsurface data for model forecasting and assimilation purposes. However, acoustic modems could be used to return the data before a full mooring turn-around and potentially reducing the amount of ship-time required.

Transport integral calculations from 1 to 2 moorings in each passage requires assumptions about the extrapolation of the single-point measurements across the passage to the side-wall boundaries and interpolation between point-wise instruments along the mooring line with depth. Thus, to convert a moored velocity record into net mass transport through the strait, the moored measurements need to be augmented with more detailed observations of cross-strait structure. Better knowledge of the width and stability of the side-wall boundary friction layer, the typically unmeasured bottom layers and improved characterization of the cross-strait structure in each passage through shipboard velocity surveys will greatly reduce uncertainty in transport estimates and help modelers make better parameter choices in simulations.

The missing near surface measurements might be achieved through acoustic tomography or high frequency radar arrays. The main advantage of these technologies is that they are truly integrative (no across strait interpolation/extrapolation is needed), they have the required high frequency sampling and they could deliver data in real time. Further piloting of coastal tomographic and high frequency radar arrays in the straits overlapping with the moored array is recommended. Finally, submarine cables that exist within the Indonesian seas also offer a potential platform to monitor ocean transport, as has been used for many decades in the Gulf Stream as part of the RAPID array (see AMOC CWP).

The interocean flux of heat and freshwater induced by the ITF does not depend just on the net transport, but also on the shape of the velocity, temperature and salinity profiles. While some proxies have been developed for ITF net volume fluxes (Sprintall and Revelard, 2014; Susanto and Song, 2015; Li et al., 2018), large changes in the profile of the ITF means that volume transports and heat/freshwater transports are not always well correlated, particularly at seasonal and longer timescales. Because of fishing pressures and vandalism, most moorings do not have a surface expression and so they do not capture the temperature and salinity of the upper $100 \mathrm{~m}$ or so. This means that moored arrays alone are unable to fully resolve the important heat and freshwater fluxes associated with the ITF. Heat transports can, however, be effectively estimated if the transport per unit depth profile is well constrained and combined with climatological temperature observations, such as from XBT transects or Argo profiles. Thus observations of the transport profile in the key ITF straits is essential to constrain the ITF heat fluxes. Less is understood about ITF freshwater flux variability. Yet variations in heat and freshwater fluxes bear directly on ocean-atmosphere exchange in the Indian Ocean (e.g., Vranes et al., 2002) so monitoring these changes may provide insight into tropical climate processes.

Ocean gliders also present new opportunities for synoptic surveys of velocity and properties in the Indonesian Seas to complement hydrographic and moored measurements. Autonomous operation and satellite communications mean that a glider could be launched and operated from a shore command post to steadily build a long-term time series of temperature, salinity, depth-integrated velocity and a suite of biogeochemical EOVs in the upper $1000 \mathrm{~m}$ across a strait or within the seas. Nonetheless, the relatively slow sampling of the glider means that high frequency variability such as internal waves are aliased into the lower frequency signals. The strong flows across straits also present a challenge for glider navigation although some strategies have been developed to successfully observe in other boundary current observing systems (e.g., Davis et al., 2012).

Downstream, the IX1 frequently repeated XBT line provides a valuable long-term record that captures the monthly upper ITF geostrophic response to the major climate modes (Liu et al., 2015), but its shallow sampling (700 m) and lack of salinity limits the accuracy of these geostrophic and heat transport estimates. In addition, large internal tides within the enclosed basins of the Indonesian seas are challenging for accurate geostrophic calculations. Careful processing is required to remove this signal from the XBT time series (e.g., Wijffels et al., 2008). While increased salinity observations from Argo may help, enhanced resolution of salinity observations near the boundaries is also needed. Thus exploring use of a CTD on a moving vessel profiler (MVP) and perhaps installation of an underway ADCP on IX1 is recommended.

\section{Hydrography of the Indonesian Seas}

There remains a scarcity of temperature, salinity and biogeochemical profiles from within the Indonesian seas. This precludes building even a seasonal picture of water mass variability, let alone tracking changes from year to year. Profiling floats (e.g., Argo) sampling of the Indonesian seas remains a challenge due to the complex topography, narrow straits, and the high likelihood of float capture or damage due to fishing operations. However, a positive development over the past decade is that the time a float spends at the sea surface to transfer data to satellite has dramatically decreased with the transition to high-bandwidth Iridium communications that significantly improves the chance of float survival (See Argo CWP). With its enclosed bathymetry, floats parked below the major sill depths $(\sim 1200 \mathrm{~m})$ are unlikely to leave the internal Indonesian seas. A stable deep water mass is also advantageous in that it allows sensor drift to be easily diagnosed and corrected.

Profiling floats also offer the opportunity to include additional sensors (e.g., microstructure, velocity biogeochemistry, rainfall and wind) beside the standard temperature-salinity (T-S). For example, parameterization of mixing from shear and strain profiles is widely used (e.g., Whalen et al., 2012) to infer dissipation of turbulent kinetic energy from the fine-scale (order $10 \mathrm{~m}$ and larger) variability in velocity and density profiles (Polzin et al., 1995). Passive Aquatic Listener (PAL) technology on profiling floats, gliders and other platforms provide estimates of wind speed and rainfall (Riser et al., 2008; Yang et al., 2015) and offer a tremendous opportunity to obtain valuable air-sea flux components within the internal Indonesian seas. Biogeochemical-Argo (BGC-Argo) sensors measuring dissolved oxygen, nitrate, $\mathrm{pH}$, Chlorophyll a, suspended particles and 
downwelling irradiance in the Indonesian Seas would also provide new and critical information on marine living resources to guide management of fisheries resources.

A float array of 6 profilers operating in the internal seas (1 in each of the Moluku, Flores, Sulawesi Seas and 3 in the Banda Sea) would be a useful initial backbone array. Several or all of these might carry biogeochemical sensors (BGC Argo CWP), which would greatly accelerate our understanding of regional productivity, carbon uptake, acidification rates and help interpret satellite ocean color data. Occasional ship-based high precision surveys of full depth biogeophysical parameters would be useful to help validate the data from the float array.

\section{Mixing and Fine-Scale Observations}

How, where and when water masses are modified and mixed in the Indonesian seas is still not known in detail, as the mixing measurements remain sparse. Of key importance to climate on many timescales is the drawdown of SST via enhanced heat transport through the thermocline driven by tidal mixing that have a major impact on both water-masses and surface heat fluxes. While a qualitative insight can be gained from fine-scale structures in density profiles delivered by profiling floats or gliders, a quantitative understanding of the processes at work requires fine-scale velocity observations and even more desirable, dissipation measurements. Direct measurements of dissipation will drive forward our understanding of local mixing and will guide parameterizations and challenge models that simulate these processes. However, direct estimates of vertical mixing through microstructure observations are costly and limited to research vessel operations (e.g., Waterhouse et al., 2014; Koch-Larrouy et al., 2015) and moorings (e.g., Moulin et al., 2018).

To measure the mixing processes near the generation sites, a combination of moorings and ship-based dissipation measurements are needed. Some insight into the generation processes can be gained from fine vertical scale $(15 \mathrm{~m})$ and high frequency measurements of the internal tides in the straits (velocity, density (T/S) at 10 minutes or higher). These measurements could coincide with the transport moorings described above that are located near some of the major generation sites. Gliders equipped with CTD, velocity and dissipation sensors could also collect detailed information across the generation sites, but the very strong tidal currents (1-2 knots) which drive the generation will prove a huge challenge to pilot the gliders. Ship-based surveys using microstructure, CTD and shear profilers are also needed, where stations are sampled over a tidal cycle.

EM-APEX (ElectroMagnetic Autonomous Profiling EXplorer) are enhanced Argo floats that include an electromagnetic subsystem to measure horizontal velocity relative to a depth-independent offset, in addition to temperature and salinity. Combining the relative velocity profiles with GPS position information delivers absolute horizontal velocity, with vertical spacing of samples of around $3 \mathrm{~m}$ (Phillips and Bindoff, 2014). These shear measurements can be used to characterize the internal wave field and estimate vertical mixing (Meyer et al., 2015, 2016). A fleet of EM-APEX floats profiling synchronously will yield a snapshot of the velocity, density and mixing structure of the interior seas, offering the potential to capture ray paths of internal tidal beams in adjacent float profiles. Due to power limitations, at present these are not suitable for long-term monitoring, but a tremendous amount could be discovered about the extent of radiated energy and its dissipation over a fixed 3-year campaign. This would be long enough to capture the interactions of the seasons, the intraseasonal and spring-neap tidal variations. Direct dissipation measurements are also being piloted on profiling floats (Argo CWP), and as this technology is matured, floats in the internal seas should be equipped with these sensors.

\section{Sea Level, SSS and SST}

Satellite missions now deliver sea level anomalies, SST and SSS routinely and globally. However, these space-based observations require in situ validation, and the signal is often degraded by the presence of cloud, aerosols and precipitation, that are common in the Indonesian seas. High temporal resolution surface flux measurements including winds, precipitation and heat flux components critical for model experiments and budget closures are lacking. Long records and high-quality reference measurements can be of great value in validating satellite retrievals and help in assessing climate records produced from a series of space-based sensors.

While the region has good coverage of high-quality sea level sites (Sealevel CWP), in situ SST and SSS data from the Indonesian seas are rarely available. Surface drifter life is short in the internal seas, and Argo floats at present sample too infrequently and are too sparse to help de-bias the satellite data. In addition, because of the fishing and vandalism pressures as well as the strong dynamic conditions, there are few moored air-sea flux reference stations in the internal Indonesian seas that might also be useful for satellite validation (e.g., see TPOS CWP). Underway thermosalinographs (TSGs) and meteorological packages from ships of opportunity could be very helpful in filling this gap and potentially could be operated on the extensive ferry system that operates throughout the Indonesian seas. Sustained SST/SSS and meteorological observations from offshore sites, such as the RAMA array (see INDOOS CWP), the wave rider or Tsunami warning sites, would also provide a valuable record.

\section{FINAL THOUGHTS AND RECOMMENDATIONS}

Understanding the variation in the ITF is crucial for understanding the coupled air-sea climate system, and the storage of the heat and fresh water that is ultimately redistributed throughout the world oceans by the thermohaline circulation. Yet despite its importance to regional and global climate, observations from this region remain limited. In this final section we suggest a way forward in the development and implementation in the coming decade of a sustained monitoring array for the transport of mass and properties along the various streams of the ITF as well as to increase our understanding of the various processes like upwelling and tidal mixing that play an important role in the water mass transformation of the region. So, while the convoluted bathymetry of the Indonesian seas means 
that moorings will likely continue to be the workhorse of any backbone transport array for the near future, our sustained array will propose a multi-platform approach including additional surveys, process studies and new technology that will go some ways to fill in the gaps that cannot be accomplished through moored arrays alone.

\section{Recommended Next Steps}

Here we provide a detailed plan that provides a framework for the needed scales and parameters of a recommended observational strategy (Figure 15). We recognize that prior to implementation, some additional "process" study measurements might be valuable to consolidate our recommended monitoring array. For example, some short-term (1-2 years) mooring measurements in the eastern arcway along the Seram Sea that feeds into the Banda Sea as well as in the shallower export passages of Sape and Sunda Strait might enable a better assessment of the contributions of these pathways to the ITF. Similarly, some model simulations have suggested that internal tides generated in other regions of the Indonesian seas might contribute to strong mixing (e.g., round the islands surrounding the Seram Sea etc.) and so might also be targeted for microstructure measurements. In addition, a process study to discriminate the coherent and non-coherent baroclinic tides might be useful to determine the interaction between the baroclinic propagative tides with the background circulation and eddy field. So while these process studies might eventually better inform our general monitoring array, our initial strategy is to recommend the observational monitoring sampling that has our highest priority (Figure 15).

\section{General Monitoring Array}

Phase 1: Intensive pilot and tidal mixing study (3-years)

(1) Instrument the major inflow and outflow straits with full moored ADCP velocity coverage (and vertically dense T and $\mathrm{S}$ measurements) to capture transport for a period of

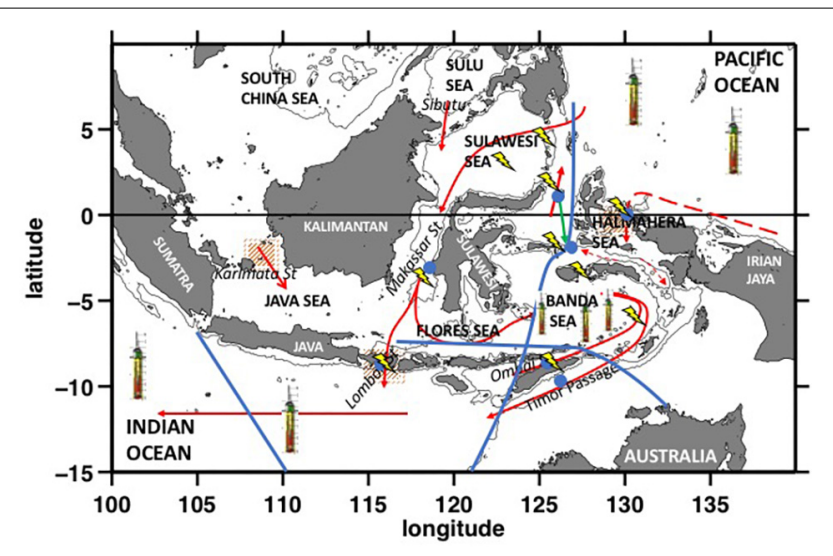

FIGURE 15 | Schematic of proposed intensive pilot study and enhanced mixing array for the Indonesian seas. The array includes (multiple) moorings in straits (blue dots); XBT transects (blue lines); acoustic tomography and/or high frequency radar (orange hatched); Argo/BGC/EM-APEX floats (float icon) and microstructure measurements (yellow lightening). Upper ocean current pathway is in red, lower pathway in green. Dashed lines indicate uncertain pathways. around 3 years. The inflow passages should include both eastern and western pathways.

(2) Use the deployment/retrieval voyages to acquire across strait velocity measurements and dissipation observations.

(3) Pilot acoustic tomography and/or high frequency radar across a few shallow straits while the moorings are in place.

(4) Densely seed the internal seas with a mixture of EM-APEX dissipation measuring, BGC Argo and regular Argo floats (total of $\sim 8-10$ floats).

(5) Encourage further mixing/dissipation, BGC and meteorological parameters from ship-based surveys during the campaign and from SOOP.

Phase 2: Replace with backbone

(1) Replace Phase 1 moorings with simpler velocity-only ADCP moorings designed for a 2-years maintenance schedule. Adjust mooring locations based on learnings from Phase 1. Explore potential of using shipboard communication or pop-up data pods to transmit collected data.

(2) Maintain a $\sim 6$ profiling float array in the internal seas, possibly all with dissipation and BGC sensors.

(3) If float returns are reliable, assess and possibly discontinue the PX2 and IX22 frequently repeated XBT lines of the internal seas. Maintain the frequently repeated IX1 line in the Indo-Australian basin as a key multidecadal record and downstream check point and enhance with ADCP and salinity measurements.

(4) If successful, continue to develop coastal acoustic tomography and high frequency radar capability, with the potential to progressively take over transport monitoring in the shallower and narrower straits.

(5) Expand in situ SSS, SST and meteorological observations of the Indonesian seas, either using TSG and meteorological packages from SOOP or shallow moorings where possible.

\section{Strategy for Enhanced Mixing Measurements}

(1) Platforms: include shipboard microstructure profilers; fast response sampling by chi-pods on moorings; CTD/LADCP or yoyo stations (for strain); profiling floats with microstructure or fast-response sensors (e.g., EM-APEX).

(2) Sampling strategy: station sampling of at least $24 \mathrm{~h}$ for dissipation to capture diurnal modulation; tidallyresolving towed sections; temporal preference to sample during spring tides when signal strongest; longer time series to extract tidal components ( $>1$ month to enable separation of M2 from S2).

(3) Locations: measurements at generation sites and along the path of the propagating tides:

(a) Generation sites:

(i) Eastern passages (Halmahera, Lifamatola, Sula and Buru straits).

(ii) Western passages (Sangihe Ridge; Sibutut Passage; Makassar and the Dewakang Strait).

(iii) Exit passages: Ombai, Lombok, and Sumba Straits. 
(b) Further away from the generation sites along the propagation pathway:

(i) Sulawesi Sea.

(ii) Banda Sea (north of Ombai, south of Sula and Buru Strait).

(iii) North of Lifamatola Passage.

(4) Companion Measurements

(a) Density (targeting the thermocline) and horizontal velocity measurements at high frequency throughout the water column to quantify the baroclinic energy at generation sites and in the far-field.

(b) Biogeochemistry information (e.g., nutrients, chlorophyll) to measure the effect of tidal mixing on potential enrichment and blooms in the surface layer.

\section{Paths to Governance and Implementation}

The recommended plan Phase 1 could benefit by being partially implemented in association with YMC or under the international IIOE-2 program. Our recommendations address many IIOE-2 priority research areas identified in Theme 4: Circulation climate variability and change (Hood et al., 2015).

Real success will rely on a closely integrated modeling and observational plan. Development of a novel set of model and analysis tools will enable examination of transport pathways, mixing processes, and make it possible to test hypotheses of remote dynamical teleconnections that are difficult to address from observations alone.

Finally, it is important to recognize that one nation alone could not expect to successfully execute and accomplish the recommended sustained monitoring strategy. The need for international co-operation to skillfully implement and fulfill the wide-ranging plan is evident. Indonesia will be a principal partner aiding in the co-ordination and facilitation of regional and political mechanisms to sustain the monitoring array, as well as to help freely deliver and distribute the data set for operational use and scientific analysis. While the logistical and organizational collaborations of the sustained array will also be achieved at senior levels of the Indonesian government, the involvement of both Indonesian and international students and early career scientists will be critical to the success in sustaining and evolving the array. While insights and quantification of transport controls and mixing processes in this key region will

\section{REFERENCES}

Aiki, H., Matthews, J., and Lamb, K. (2011). Modeling and energetics of tidally generated wave trains in the Lombok Strait: impact of the Indonesian Throughflow. J. Geophys. Res. 116:C03023. doi: 10.1029/2010JC006589

Alford, M. A., Gregg, M. C., and Ilyas, M. (1999). Diapycnal mixing in the Banda Sea: results of the first microstructure measurements in the Indonesian Throughflow. J. Geophys. Res. 26, 2741-2744. doi: 10.1029/1999GL002337

Alory, G., Wijffels, S. E., and Meyers, G. (2007). Observed temperature trends in the Indian Ocean over 1960-1999 and associated mechanisms. Geophys. Res. Lett. 34:L02606. doi: 10.1029/2006GL028044 have application in global modeling systems used for ocean and climate forecasts, it is also expected that a significant part of the outcome of this sustained array will be to improve local marine resource management and conservation practices in the maritime continent.

\section{AUTHOR CONTRIBUTIONS}

JS led the writing, editing, and organization of the manuscript. AG, SW, MF, and SH led and wrote sections. AK-L and HP led and wrote significant subsections. DN, AN, KP, RS, BS, BP-M, DY, NR, SS, AK, ZA, AW, HZ, TN, JA, RB-B, JC, FL, BA, $\mathrm{AR}$, and $\mathrm{AS}$ contributed to the writing of sections. All authors contributed comments.

\section{FUNDING}

JS acknowledges funding to support her effort by the National Science Foundation under Grant Number OCE1736285 and NOAA's Climate Program Office, Climate Variability and Predictability Program under Award Number NA17OAR4310257. SH was supported by the National Natural Science Foundation of China (Grant 41776018) and the Key Research Program of Frontier Sciences, CAS (QYZDBSSW-SYS023). HP acknowledges support from the Australian Government's National Environmental Science Programme. HZ acknowledges support from National Science Foundation under Grant No. 41876009. RS was supported by National Science Foundation Grant No. OCE-07-25935; Office of Naval Research Grant No. N00014-08-01-0618 and National Aeronautics and Space Administration Grant No. 80NSSC18K0777. SW, MF, and BS were supported by Center for Southern Hemisphere Oceans Research (CSHOR), which is a joint initiative between the Qingdao National Laboratory for Marine Science and Technology (QNLM), CSIRO, University of New South Wales and University of Tasmania.

\section{SUPPLEMENTARY MATERIAL}

The Supplementary Material for this article can be found online at: https://www.frontiersin.org/articles/10.3389/fmars. 2019.00257/full\#supplementary-material

Andersson, H. C., and Stigebrandt, A. (2005). Regulation of the Indonesian throughflow by baroclinic draining of the North Australian Basin. Deep Sea Res. Part I Oceanogr. Res. Pap. 52, 2214-2233. doi: 10.1016/j.dsr.2005. 06.014

Annamalai, H., Kida, S., and Hafner, J. (2010). Potential impact of the tropical Indian Ocean - Indonesian Seas on El Niño characteristics. J. Clim. 23, 39333952. doi: 10.1175/2010jcli3396.1

Ansong, J. K., Arbic, B. K., Buijsman, M. C., Richman, J. G., Shriver, J. F., and Wallcraft, A. J. (2015). Indirect evidence for substantial damping of low-mode internal tides in the open ocean. J. Geophys. Res. Oceans 120, 6057-6071. doi: 10.1002/2015JC010998 
Ayers, J., Strutton, P., Coles, V. J., Hood, R., and Matear, R. (2014). Indonesian throughflow nutrient fluxes and their potential impact on Indian Ocean productivity. Geophys. Res. Lett. 41, 5060-5067. doi: 10.1002/2014GL060593

Baranowski, D. B., Flatau, M. K., Flatau, P. J., and Matthews, A. J. (2016). Phase locking between atmospheric convectively coupled equatorial Kelvin waves and the diurnal cycle of precipitation over the Maritime Continent. Geophys. Res. Lett. 43, 8269-8276. doi: 10.1002/2016gl069602

Castruccio, F. S., Curchitser, E. N., and Kleypas, J. A. (2013). A model for quantifying oceanic transport and mesoscale variability in the Coral Triangle of the Indonesian/Philippines Archipelago. J. Geophys. Res. Oceans 118, 61236144. doi: 10.1002/2013JC009196

Cheng, L., Trenberth, K. E., Fasullo, J., Boyer, T., Abraham, J., and Zhu, J. (2017). Improved estimates of ocean heat content from 1960 to 2015. Sci. Adv. 3:1601545. doi: 10.1126/sciadv.1601545

Clarke, A. J., and Liu, X. (1994). Interannual sea level in the Northern and Eastern Indian Ocean. J. Phys. Oceanogr. 24, 1224-1235. doi: 10.1175/1520-0485(1994) 024<1224:ISLITN>2.0.CO;2

Cresswell, G. R., and Luick, J. L. (2001). Current measurements in the Halmahera Strait. J. Geophys. Res. 106, 13945-13951. doi: 10.1029/2000jc000688

Crueger, T., Zinke, J., and Pfeiffer, M. (2009). Patterns of pacific decadal variability recorded by Indian Ocean corals. Int. J. Earth Sci. 98, 41-52. doi: 10.1007/ s00531-008-0324- 1

Davis, R. E., Kessler, W. S., and Sherman, J. T. (2012). Gliders measure western boundary current transport from the south pacific to the equator. J. Phys. Oceanogr. 42, 2001-2013. doi: 10.1175/jpo-d-12-022.1

Delman, A. S., McClean, J. L., Sprintall, J., Talley, L. D., and Bryan, F. O. (2018). Process-specific contributions to anomalous Java mixed layer cooling during positive IOD events. J. Geophys. Res. Oceans 123, 4153-4176. doi: 10.1029/ 2017JC013749

Delman, A. S., Sprintall, J., McClean, J. L., and Talley, L. D. (2016). Anomalous Java cooling at the initiation of positive IOD events. J. Geophys. Res. Oceans 121, 5805-5824. doi: 10.1002/2016JC01163

Dong, L., and McPhaden, M. J. (2016). Interhemispheric SST gradient trends in the Indian ocean prior to and during the recent global warming hiatus. J. Clim. 29, 9077-9095. doi: 10.1175/jcli-d-16-0130.1

Drushka, K., Sprintall, J., Gille, S. T., and Brodjonegoro, I. (2010). Vertical structure of Kelvin waves in the Indonesian Throughflow exit passages. J. Phys. Oceanogr. 40, 1965-1987. doi: 10.1175/2010jpo4380.1

Drushka, K., Sprintall, J., Gille, S. T., and Wijffels, S. (2012). In situ observations of Madden-Julian Oscillation mixed layer dynamics in the Indian and Western Pacific Oceans. J. Clim. 25, 2306-2328. doi: 10.1175/jcli-d-11-00203.1

Du, Y., Zhang, Y., Feng, M., Wang, T., Zhang, N., and Wijffels, S. E. (2015). Decadal trends of the upper ocean salinity in the tropical Indo-Pacific since mid-1990s. Sci. Rep. 5:16050. doi: 10.1038/srep16050

England, M. H., McGregor, S., Spence, P., Meehl, G. A., Timmermann, A., Cai, W., et al. (2014). Recent intensification of wind-driven circulation in the Pacific and the ongoing warming hiatus. Nat. Clim. Change 4, 222-227. doi: 10.1038/ nclimate 2106

Fang, G., Susanto, R. D., Soesilo, I., Zheng, Q., Fangli, Q., Zexun, W., et al. (2005). A note on the South China Sea shallow interocean circulation. Adv. Atmos. Sci. 22, 946-954. doi: 10.1007/bf02918693

Fang, G. H., Susanto, R. D., Wirasantosa, S., Qiao, F. L., Supangat, A., Fan, B., et al. (2010). Volume, heat and freshwater transports from the South China Sea to Indonesian seas in the boreal winter of 2007-2008. J. Geophys. Res. 115:C12020. doi: 10.1029/2010JC006225

Feng, M., Benthuysen, J., Zhang, N., and Slawinski, D. (2015). Freshening anomalies in the Indonesian throughflow and impacts on the Leeuwin Current during 2010-2011. Geophys. Res. Lett. 42, 8555-8562. doi: 10.1002/ 2015GL065848

Feng, M., Böning, C. W., Biastoch, A., Behrens, E., Weller, E., and Masumoto, Y. (2011). The reversal of the multi-decadal trends of the equatorial Pacific easterly winds, and the Indonesian Throughflow and Leeuwin Current transports. Geophys. Res. Lett. 38:L11604. doi: 10.1029/2011GL047291

Feng, M., and Meyers, G. (2003). Interannual variability in the tropical Indian Ocean: a two-year time scale of Indian Ocean Dipole. Deep Sea Res. 50, 2263-2284. doi: 10.1016/s0967-0645(03)00056-0

Feng, M., Zhang, N., Liu, Q., and Wijffels, S. (2018). The Indonesian throughflow, its variability and centennial change. Geosci. Lett. 5:3.
Feng, M., Zhang, X., Sloyan, B., and Chamberlain, M. (2017). Contribution of the deep ocean to the centennial changes of the Indonesian Throughflow. Geophys. Res. Lett. 44, 2859-2867. doi: 10.1002/2017GL072577

Ffield, A., and Gordon, A. L. (1992). Vertical mixing in the Indonesian thermocline. J. Phys. Oceanogr. 22, 184-195. doi: 10.1175/1520-0485(1992)022<0184: vmitit>2.0.co;2

Ffield, A., and Gordon, A. L. (1996). Tidal mixing signatures in the Indonesian Seas. J. Phys. Oceanogr. 26, 1924-1937. doi: 10.1175/1520-0485(1996)026<1924: tmsiti> 2.0.co;2

Gordon, A. L., Huber, B. A., Metzger, E. J., Susanto, R. D., Hurlburt, H. E., and Adi, T. R. (2012). South china sea throughflow impact on the Indonesian Throughflow. Geophys. Res. Lett. 39:L11602.

Gordon, A. L., Ma, S., Olson, D. B., Hacker, P., Ffield, A., Talley, L. D., et al. (1997). Advection and diffusion of Indonesian Throughflow water within the Indian ocean south equatorial current. Geophys. Res. Lett. 24, 2573-2576. doi: $10.1029 / 97 \mathrm{gl01061}$

Gordon, A. L., Napitu, A., Huber, B. A., Gruenburg, L. K., Pujiana, K., Agustiadi, T., et al. (2019). Makassar strait throughflow seasonal and interannual variability, an overview. J. Geophys. Res. Oceans. 124. doi: 10.1029/2018JC014502

Gordon, A. L., Sprintall, J., Van Aken, H. M., Susanto, D., Wijffels, S., Molcard, R., et al. (2010a). The Indonesian Throughflow during 2004-2006 as observed by the INSTANT program in modeling and observing the Indonesian Throughflow. Dyn. Atmos. Oceans 50, 115-128. doi: 10.1016/j.dynatmoce.2009. 12.002

Gordon, A. L., Sprintall, J., Wijffels, S., Susanto, D., and Molcard, R. (2010b). "Interocean exchange of thermocline water: Indonesian throughflow; "Tassie" leakage; agulhas leakage," in Proceedings of OceanObs'09: Sustained Ocean Observations and Information for Society, Vol. 2, eds J. Hall, D. E. Harrison, and D. Stammer (Venice: ESA Publication). doi: 10.5270/OceanObs09. cwp. 37

Gordon, A. L., and Susanto, R. D. (2001). Banda Sea surface-layer divergence. Ocean Dyn. 52, 2-10.

Gordon, A. L., Susanto, R. D., Ffield, A., Huber, B. A., Pranowo, W., and Wirasantosa, S. (2008). Makassar Strait Throughflow, 2004 to 2006. Geophys. Res. Lett. 35:L24605.

Gordon, A. L., Susanto, R. D., and Vranes, K. (2003). Cool Indonesian throughflow is a consequence of restricted surface layer flow. Nature 425, 824-828. doi: 10.1038 /nature02038

Gruenburg, L., and Gordon, A. L. (2018). Variability in Makassar Strait heat flux and its effect on the eastern tropical Indian ocean. Oceanography 31, 80-87.

Hagos, S. M., Zhang, C., Geng, Z., Burleyson, C. D., De Mott, C., Kerns, B., et al. (2016). The impact of the diurnal cycle on the propagation of Madden-Julian Oscillation convection across the Maritime Continent. J. Adv. Model. Earth Syst. 8, 1552-1564. doi: 10.1002/2016ms000725

Han, W., Vialard, J., and McPhaden, M. J. (2014). Indian ocean decadal variability: a review. Bull. Am. Meteorol. Soc. 95, 1679-1703. doi: 10.1175/BAMS-D-1300028.1

Hautala, S. L., Sprintall, J., Potemra, J. T., Chong, J. C., Pandoe, W., Bray, N., et al. (2001). Velocity structure and transport of the Indonesian Throughflow in the major straits restricting flow into the Indian Ocean. J. Geophys. Res. 106:19527. doi: 10.1029/2000jc000577

Hennekam, R., Zinke, J., van Sebille, E., Ten Have, M., Brummer, G. J. A., and Reichart, G. J. (2018). Cocos (Keeling) Corals Reveal 200 years of multidecadal modulation of southeast Indian ocean hydrology by Indonesian throughflow. Paleoceanogr. Paleoclimatol. 33, 48-60. doi: 10.1002/2017PA003181

Hood, R. R., Bange, H. W., Beal, L., Beckley, L. E., Burkill, P., Cowie, G. L., et al. (2015). Science Plan of the Second International Indian Ocean Expedition (IIOE-2): A Basin-Wide Research Program, Newark, DE: Scientific Committee on Oceanic Research.

Hu, D. L., Wu, W., Cai, A. S., Gupta, A., Ganachaud, B., Qiu, A., et al. (2015). Pacific western boundary currents and their roles in climate. Nature 522, 299-308. doi: $10.1038 /$ nature 14504

$\mathrm{Hu}, \mathrm{S}$., and Sprintall, J. (2016). Interannual variability of the Indonesian Throughflow: the salinity effect. J. Geophys. Res. Oceans 121, 2596-2615. doi: 10.1002/2015JC011495

Hu, S., and Sprintall, J. (2017). Observed strengthening of interbasin exchange via the Indonesian seas due to rainfall. Geophys. Res. Lett. 44, 1448-1456. doi: 10.1002/2016GL072494 
Inness, P. M., and Slingo, J. M. (2006). The interaction of the madden-Julian oscillation with the maritime continent in a GCM. Q. J. R. Meteorol. Soc. 132, 1645-1667. doi: 10.1256/qj.05.102

Jochum, M., and Potemra, J. (2008). Sensitivity of tropical rainfall to Banda Sea diffusivity in the community climate system model. J. Clim. 21, 6445-6454. doi: $10.1175 / 2008$ jcli2230.1

Kartadikaria, A. R., Miyazawa, Y., Varlamov, S. M., and Nadaoka, K. (2011). Ocean circulation for the Indonesian seas driven by tides and atmospheric forcings: comparison to observational data. J. Geophys. Res. Oceans 116, 1-21.

Kida, S., and Wijffels, S. (2012). The impact of the Indonesian Throughflow and tidal mixing on the summertime sea surface temperature in the western Indonesian Seas. J. Geophys. Res. Oceans 117:C09007.

Koch-Larrouy, A., Atmadipoera, A., van Beek, P., Madec, G., Aucan, J., Lyard, F., et al. (2015). Estimates of tidal mixing in the Indonesian archipelago from multidisciplinary INDOMIX in-situ data. Deep Sea Res. Part I Oceanogr. Res. Pap. 106, 136-153. doi: 10.1016/j.dsr.2015.09.007

Koch-Larrouy, A., Lengaigne, M., Terray, P., Madec, G., and Masson, S. (2010). Tidal mixing in the Indonesian Seas and its effect on the tropical climate system. Clim. Dyn. 34, 891-904. doi: 10.1007/s00382-009-0642-4

Koch-Larrouy, A., Madec, G., Bouruet-Aubertot, P., Gerkema, T., Bessieres, L., and Molcard, R. (2007). On the transformation of Pacific Water into Indonesian Throughflow Water by internal tidal mixing. Geophys. Res. Lett. 34:L04604.

Koch-Larrouy, A., Madec, G., Iudicone, D., Molcard, R., and Atmadipoera, A. (2008). Physical processes contributing to the water mass transformation of the Indonesian Throughflow. Ocean Dyn. 58, 275-288. doi: 10.1007/s10236-0080154-5

Kosaka, Y., and Xie, S.-P. (2013). Recent global-warming hiatus tied to equatorial Pacific surface cooling. Nature 501, 403-407. doi: 10.1038/nature12534

Kuehl, J. J., and Sheremet, V. A. (2009). Identification of a cusp catastrophe in a gap-leaping western boundary current. J. Mar. Res. 67, 25-42. doi: 10.1357/ 002224009788597908

Kuswardani, R. T. D., and Qiao, F. (2014). Influence of Indonesian Throughflow on the upwelling off the east coast of South Java. Chin. Sci. Bull. 59, 4516-4523. doi: 10.1007/s11434-014-0549-2

Lee, S. K., Park, W., Baringer, M. O., Gordon, A. L., Huber, B., and Liu, Y. (2015). Pacific origin of the abrupt increase in Indian Ocean heat content during the warming hiatus. Nat. Geosci. 8, 445-449. doi: 10.1038/ngeo2438

Lee, T., and McPhaden, M. J. (2008). Decadal phase changes in large-scale sea level and winds in the Indo-Pacific region at the end of the 20th century. Geophys. Res. Lett. 35:L01605. doi: 10.1029/2007GL032419

Li, M., Gordon, A. L., Wei, J., Gruenburg, L. K., and Jiang, G. (2018). Multi-decadal timeseries of the Indonesian throughflow. Dyn. Atmos. Oceans 81, 84-95. doi: 10.1016/j.dynatmoce.2018.02.001

Li, S., Wei, Z., Susanto, R. D., Zhu, Y., Setiawan, A., Xu, T., et al. (2017). Observations of intraseasonal variability in the Sunda Strait throughflow. J. Oceanogr. 74, 541-547. doi: 10.1007/s10872-018-0476-y

Li, Y., Han, W., and Zhang, L. (2017). Enhanced decadal warming of the southeast Indian Ocean during the recent global surface warming slowdown. Geophys. Res. Lett. 44, 9876-9884. doi: 10.1002/2017gl075050

Liu, Q., Feng, M., Wang, D., and Wijffels, S. (2015). Interannual Variability of the Indonesian Throughflow transport: a revisit based on 30 year expendable bathythermograph data. J. Geophys. Res. Oceans 120, 8270-8282. doi: 10.1002/ 2015JC011351

Liu, Q., Huang, R. X., Wang, D., Xie, Q., and Huang, Q. (2006). Interplay between the Indonesian throughflow and the South China Sea throughflow. Chin. Sci. Bull. 51, 50-58. doi: 10.1007/s11434-006-9050-x

Liu, Q., Wang, D., Zhou, W., Xie, Q., and Zhang, Y. (2010). Covariation of the Indonesian throughflow and South China Sea throughflow associated with the 1976/77 regime shift. Adv. Atmos. Sci. 27, 87-94. doi: 10.1007/s00376-0098061-3

Liu, W., Xie, S.-P., and Lu, J. (2016). Tracking ocean heat uptake during the surface warming hiatus. Nat. Commun. 7:10926. doi: 10.1038/ncomms10926

Matthews, J. P., Aiki, H., Masuda, S., Awaji, T., and Ishikawa, Y. (2011). Monsoon regulation of Lombok Strait internal waves. J. Geophys. Res. 116:C05007. doi: 10.1029/2010JC006403

Mayer, M., Alonso Balmaseda, M., and Haimberger, L. (2018). Unprecedented 2015/2016 Indo-Pacific heat transfer speeds up tropical Pacific heat recharge. Geophys. Res. Lett. 45, 3274-3284. doi: 10.1002/2018GL077106
McClean, J. L., Ivanova, D. P., and Sprintall, J. (2005). Remote origins of interannual variability in the Indonesian Throughflow region from data and a global Parallel Ocean Program simulation. J. Geophys. Res. 110:C10013. doi: 10.1029/2004JC002477

Merrifield, M. A., and Maltrud, M. (2011). Regional sea level trends due to Pacific wind intensification. Geophys. Res. Lett. 38:L21605. doi: 10.1029/ 2011 GL049576

Meyer, A., Polzin, K. L., Sloyan, B. M., and Phillips, H. E. (2016). Internal waves and mixing near the Kerguelen Plateau. J. Phys. Oceanogr. 46, 417-437. doi: 10.1175/jpo-d-15-0055.1

Meyer, A., Sloyan, B. M., Polzin, K. L., Phillips, H. E., and Bindoff, N. L. (2015). Mixing variability in the Southern Ocean. J. Phys. Oceanogr. 45, 966-987. doi: 10.1175/jpo-d-14-0110.1

Moulin, A. J., Moum, J. N., and Shroyer, E. L. (2018). Evolution of turbulence in the diurnal warm layer. J. Phys. Oceanogr. 48, 383-396. doi: 10.1175/jpo-d-170170.1

Moum, J. N., de Szoeke, S. P., and Smyth, W. D. (2014). Air-sea interactions from westerly wind bursts during the November 2011 MJO in the Indian Ocean. Bull. Am. Meteor. Soc. 95, 1185-1199. doi: 10.1175/bams-d-1200225.1

Nagai, T., and Hibiya, T. (2015). Internal tides and associated vertical mixing in the Indonesian Archipelago. J. Geophys. Res. Oceans 120, 3373-3390. doi: $10.1002 / 2014$ jc010592

Napitu, A. M. (2017). Response of the Indonesian Seas and its Potential Feedback to the Madden Julian Oscillation. Ph.D. dissertation, Columbia University, New York, NY. doi: 10.7916/D8086HSK

Napitu, A. M., Gordon, A. L., and Pujiana, K. (2015). Intraseasonal sea surface temperature variability across the Indonesian sea. J. Clim. 28, 8710-8727. doi: 10.1175/jcli-d-14-00758.1

Napitu, A. M., Pujiana, K., and Gordon, A. L. (2019). The madden-Julian oscillation's impact on the Makassar strait surface layer transport. J. Geophys. Res. 124. doi: 10.1029/2018JC014729

Neale, R. B., Richter, J. H., and Jochum, M. (2008). The Impact of convection on ENSO: from a delayed oscillator to a series of events. J. Clim. 21, 5904-5924. doi: $10.1175 / 2008$ jcli2244.1

Newton, A. (2018). Tropical interchange. Nat. Geosci. 11:20. doi: 10.1038/s41561017-0049-5

Nieves, V., Willis, J. K., and Patzert, W. C. (2015). Recent hiatus caused by decadal shift in Indo-Pacific heating. Science 349, 532-535. doi: 10.1126/science. aaa4521

Niwa, Y., and Hibiya, T. (2011). Estimation of baroclinic tide energy available for deep ocean mixing based on three-dimensional global numerical simulations. Oceanogr. J. 67, 493-502. doi: 10.1007/s10872-011-0052-1

Nugroho, D. (2017). Tides in a OGCM in the Indonesian Seas. Toulouse: Paul Sabatier University.

Nugroho, Y., Koch-Larrouy, A., Gaspar, P., Lyard, F., Reffray, G., Tranchant, B., et al. (2017). Modelling explicit tides in the Indonesian seas: an important process for surface sea water properties. Mar. Pollut. Bull. 131(Pt B), 7-18. doi: 10.1016/j.marpolbul.2017.06.033

Pariwono, J. I. (1986). Wind Stress, Mean Sea Level and Inter-Ocean Transport in the Australasian Region. Ph.D. thesis, Flinders University, Bedford Park.

Peatman, S. C., Matthews, A. J., and Stevens, D. P. (2014). Propagation of the Madden-Julian Oscillation through the Maritime Continent and scale interaction with the diurnal cycle of precipitation. Q. Meteorol. J. R. Soc. 140, 814-825. doi: 10.1002/qj.2161

Phillips, H. E., and Bindoff, N. L. (2014). On the nonequivalent barotropic structure of the Antarctic Circumpolar Current: an observational perspective. J. Geophys. Res. Oceans 119, 5221-5243. doi: 10.1002/2013JC009516

Phillips, H. E., Wijffels, S. E., and Feng, M. (2005). Interannual variability in the freshwater content of the Indonesian-Australian Basin. Geophys. Res. Lett. 32:L03603. doi: 10.1029/2004GL021755

Polzin, K. L., Toole, J. M., and Schmitt, R. W. (1995). Finescale parameterizations of turbulent dissipation. J. Phys. Oceanogr. 25, 306-328. doi: 10.1038/s41598018-28554-z

Potemra, J. T. (1999). Seasonal variations of the Pacific to Indian Ocean throughflow. J. Phys. Oceanogr. 29, 2930-2944. doi: 10.1175/1520-0485(1999) $029<2930$ :svouot $>2.0$. co; 2 
Pujiana, K., Gordon, A. L., Metzger, E. J., and Ffield, A. L. (2012). The makassar strait pycnocline variability at 20-40 days. Dyn. Atmos. Oceans 53, 17-35. doi: 10.1016/j.dynatmoce.2012.01.001

Pujiana, K., Gordon, A. L., and Sprintall, J. (2013). Intraseasonal Kelvin wave in makassar strait. J. Geophys. Res. Oceans 118, 2023-2034. doi: 10.1002/jgrc. 20069

Pujiana, K., Gordon, A. L., Sprintall, J., and Susanto, D. (2009). Intraseasonal variability in the makassar strait thermocline. J. Mar. Res. 67, 757-777. doi: 10.1357/002224009792006115

Pujiana, K., McPhaden, M. J., Gordon, A. L., and Napitu, A. M. (2019). Unprecedented response of Indonesian throughflow to anomalous Indo-Pacific climatic forcing in 2016. J. Geophys. Res. 124. doi: 10.1029/2018JC014574

Pujiana, K., Moum, J. N., and Smyth, W. D. (2018). The role of subsurface turbulence in redistributing upper ocean heat, freshwater and momentum in response to the Madden-Julian Oscillation in the equatorial Indian Ocean. J. Phys. Oceanogr. 48, 197-220. doi: 10.1175/JPO-D-17-0146.1

Purba, M. (2007). Dynamics of South of Java - Sumbawa Island in Southeast Monsoon, Vol. 17. Torani: Jurnal Ilmu Kelautan dan Perikanan.

Qu, T., Du, Y., Meyers, G., Ishida, A., and Wang, D. (2005). Connecting the tropical Pacific with Indian Ocean through South China Sea. Geophys. Res. Lett. 32:L24609. doi: 10.1029/2005GL024698

Qu, T., and Meyers, G. (2005). Seasonal Characteristics of Circulation in the Southeastern Tropical Indian Ocean, Notes and Correspondence. Boston, MA: American Meteorological Society, 255-267.

Ray, R., and Susanto, R. D. (2016). Tidal mixing signatures in the Indonesian seas from high-resolution sea surface temperature data. Geophys. Res. Lett. 43, 8115-8123. doi: 10.1002/2016gl069485

Riser, S., Nystuen, J., and Rogers, A. (2008). Monsoon effects in the Bay of Bengal inferred from profiling float-based measurements of wind speed and rainfall. Limnol. Oceanogr. 53, 2080-2093. doi: 10.4319/lo.2008.53.5_part_2.2080

Robertson, R., and Ffield, A. (2005). M2 baroclinic tides in the Indonesian Seas. Oceanography 18, 62-73. doi: 10.5670/oceanog.2005.06

Sasaki, H., Kida, S., Furue, R., Nonaka, M., and Masumoto, Y. (2018). An increase of the Indonesian throughflow by internal tidal mixing in a high-resolution quasi-global ocean simulation. Geophys. Res. Lett. 45, 8416-8424.

Schiller, A. (2004). Effects of explicit tidal forcing in an OGCM on the water-mass structure and circulation in the Indonesian throughflow region. Ocean Model. 6, 31-49. doi: 10.1016/s1463-5003(02)00057-4

Schiller, A., Godfrey, S., Macintosh, P., Meyers, G., and Wijffels, S. E. (1998). Seasonal near-surface dynamics and thermodynamics of the Indian ocean and Indonesian throughflow in a global ocean general circulation model. J. Phys. Oceanogr. 28, 2288-2312. doi: 10.1175/1520-0485(1998)028<2288:snsdat $>2$. $0 . \operatorname{co} ; 2$

Schwarzkopf, F. U., and Böning, C. W. (2011). Contribution of Pacific wind stress to multi-decadal variations in upper-ocean heat content and sea level in the tropical south Indian Ocean. Geophys. Res. Lett. 38:L12602. doi: 10.1029/ 2011GL047651

Sen Gupta, A., McGregor, S., Sebille, E., Ganachaud, A., Brown, J., and Santoso, A. (2016). Future changes to the Indonesian throughflow and Pacific circulation: the differing role of wind and deep circulation changes. Geophys. Res. Lett. 43, 1669-1678. doi: 10.1002/2016gl067757

Shinoda, T., Han, W., Metzger, E. J., and Hurlburt, H. E. (2012). Seasonal variation of the Indonesian Throughflow in makassar strait. J. Phys. Oceanogr. 42, 1099-1123. doi: 10.1175/JPO-D-11-0120.1

Shriver, J. F., Arbic, B. K., Richman, J. G., Ray, R. D., Metzger, E. J., Wallcraft, A. J., et al. (2012). An evaluation of the barotropic and internal tides in a high-resolution global ocean circulation model. J. Geophys. Res. Oceans 117, $1-14$.

Sprintall, J., Gordon, A., Murtugudde, R., and Susanto, D. (2000). A semi-annual Indian Ocean forced Kelvin wave observed in the Indonesian Seas in May 1997. J. Geophys. Res. 105, 17217-17230. doi: 10.1029/2000jc900065

Sprintall, J., Gordon, A. L., Koch-Larrouy, A., Lee, T., Potemra, J. T., Pujiana, K., et al. (2014). The Indonesian Seas and their impact on the Coupled Ocean Climate System. Nat. Geosci. 7, 487-492. doi: 10.1038/NGEO2188

Sprintall, J., and Revelard, A. (2014). The Indonesian throughflow response to Indo-Pacific climate variability. J. Geophys. Res. Oceans 119, 1161-1175. doi: 10.1002/2013JC009533
Sprintall, J., Wijffels, S., Molcard, R., and Jaya, I. (2009). Direct estimates of the Indonesian Throughflow entering the Indian Ocean. J. Geophyis. Res. 114:C07001. doi: 10.1029/2008JC005257

Susanto, R. D., Fang, G., Soesilo, I., Zheng, Q., Qiao, F., Wei, Z., et al. (2010). New Surveys of a branch of the Indonesian Throughflow. EOS Trans. AGU 91, 261-263. doi: 10.1029/2010EO300002

Susanto, R. D., Ffield, A., Gordon, A. L., and Adi, T. R. (2012). Variability of Indonesian Throughflow within makassar strait: 2004-2009. J. Geophys. Res. Oceans 117:C09013.

Susanto, R. D., and Gordon, A. L. (2005). Velocity and transport of Indonesian throughflow in Makassar Strait. J. Geophys. Res. 110:C01005. doi: 10.1029/ 2004JC002425

Susanto, R. D., Mitnik, L., and Zheng, Q. (2005). Ocean internal waves observed in the Lombok strait. Oceanography 18, 80-87. doi: 10.5670/oceanog.2005.08

Susanto, R. D., and Song, Y. T. (2015). Indonesian throughflow proxy from satellite altimeters and gravimeters. J. Geophys. Res. Oceans 120, 2844-2855. doi: 10. 1002/2014jc010382

Susanto, R. D., Wei, Z., Adi, T. R., Zheng, Q., Fang, G., Bin, F., et al. (2016). Oceanography surrounding Krakatau Volcano in the Sunda Strait, Indonesia. Oceanography 29, 264-272. doi: 10.5670/oceanog.2016.31

Susanto, R. D., Zexun, W., Rameyo, A., Bin, F., Shujiang, L., and Guohong, F. (2013). Observations of the Karimata Strait throughflow from December 2007 to November 2008. Acta Oceanol. Sin. 32, 1-6. doi: 10.1007/s13131-0130307-3

Talley, L. D., and Sprintall, J. (2005). Deep expression of the Indonesian Throughflow: Indonesian intermediate water in the south equatorial current. J. Geophys. Res. 110:C10009. doi: 10.1029/2004JC002826

Tessler, Z. D., Gordon, A. L., and Jackson, C. R. (2012). Early stage soliton observations in the Sulu Sea. J. Phys. Oceanogr. 42, 1327-1336. doi: 10.1175/ jpo-d-11-0165.1

Tozuka, T., Qu, T., Masumoto, Y., and Yamagata, T. (2009). Impacts of the South China Sea throughflow on seasonal and interannual variations of the Indonesian throughflow. Dyn. Atmos. Oceans 47, 73-85. doi: 10.1016/j. dynatmoce.2008.09.001

Tozuka, T., Qu, T., and Yamagata, T. (2007). Dramatic impact of the South China Sea on the Indonesian throughflow. Geophys. Res. Lett. 34:L12612. doi: 10.1029/ 2007GL030420

Trenary, L. L., and Han, W. (2013). Local and remote forcing of decadal sea level and thermocline depth variability in the South Indian Ocean. J. Geophys. Res. Oceans 118, 381-398. doi: 10.1029/2012jc008317

Ummenhofer, C. C., Biastoch, A., and Böning, C. W. (2017). Multidecadal Indian Ocean variability linked to the Pacific and implications for preconditioning Indian Ocean dipole events. J. Clim. 30, 1739-1751. doi: 10.1175/jcli-d-160200.1

Valsala, V., Maksyutov, S., and Murtugudde, R. (2011). Interannual to interdecadal variabilities of the Indonesian Throughflow source water pathways in the Pacific Ocean. J. Phys. Oceanogr. 41, 1921-1940. doi: 10.1175/2011JPO 4561.1

van Aken, H. M., Brodjonegoro, I. S., and Jaya, I. (2009). The deep-water motion through the Lifamatola Passage and its contribution to the Indonesian throughflow. Deep Res. Part I 56, 1203-1216. doi: 10.1016/j.dsr.2009.02.001

Vargas-Hernandez, J., Wijffels, S., Meyers, G., Belo de Couto, A., and Holbrook, N. (2015). Decadal characterization of Indo-Pacific Ocean subsurface temperature modes in SODA reanalysis. J. Clim. 28, 6113-6132. doi: 10.1175/jcli-d-1400700.1

Vecchi, G. A., Soden, B. J., Wittenberg, A. T., Held, I. M., Leetma, A., and Harrison, M. J. (2006). Weakening of tropical Pacific atmospheric circulation due to anthropogenic forcing. Nature 441, 73-76. doi: 10.1038/nature04744

Vranes, K., Gordon, A. L., and Ffield, A. (2002). The heat transport of the Indonesian Throughflow and implications for the Indian Ocean heat budget. Deep Sea Res. 49, 1391-1410. doi: 10.1016/s0967-0645(01)00150-3

Wainwright, L., Meyers, G., Wijffels, S., and Pigot, L. (2008). Change in the Indonesian Throughflow with the climatic shift of 1976/77. Geophys. Res. Lett. 35:L03604. doi: 10.1029/2007GL031911

Wang, D., Liu, Q., Huang, R. X., Du, Y., and Qu, T. (2006). Interannual variability of the South China Sea throughflow inferred from wind data and an ocean data assimilation product. Geophys. Res. Lett. 33:L14605. 
Wang, Y., Xu, T., Li, S., Susanto Dwi, R., Agustiadi, T., Trenggono, M., et al. (2019). Seasonal variation of water transport through the Karimata Strait. Acta Oceanol. Sin. 38, 47-57. doi: 10.1007/s13131-018-1224-2

Wang, Z., and Yuan, D. (2012). Nonlinear dynamics of two western boundary currents colliding at a gap. J. Phys. Oceanogr. 42, 2030-2040. doi: 10.1175/jpod-12-05.1

Wang, Z., and Yuan, D. (2014). Multiple equilibria and hysteresis of two unequaltransport western boundary currents colliding at a gap. J. Phys. Oceanogr. 44, 1873-1885. doi: 10.1175/jpo-d-13-0234.1

Waterhouse, A. F., MacKinnon, J. A., Nash, J. D., Alford, M. H., Kunze, E., Simmons, H. L., et al. (2014). Global patterns of diapycnal mixing from measurements of the turbulent dissipation rate. J. Phys. Oceanogr. 44, 18541872. doi: 10.1175/JPO-D-13-0104.1

Wei, Z., Li, S., Susanto Dwi, R., Wang, Y., Fan, B., Xu, T., et al. (2019). An overview of 10-year observation of the South China Sea branch of the Pacific to Indian Ocean throughflow at the Karimata Strait. Acta Oceanol. Sin. 38, 1-11. doi: 10.1007/s13131-018-0000-0

Wei, Z. X., Fang, G. H., Susanto, R. D., Adi, T. R., Fan, B., Setiawan, A., et al. (2015). Tidal elevation, current and energy flux in the area between the South China Sea and Java Sea. Ocean Sci. 12, 2831-2861. doi: 10.5194/osd-12-2831-2015

Whalen, C. B., Talley, L. D., and MacKinnon, J. A. (2012). Spatial and temporal variability of global ocean mixing inferred from Argo profiles. Geophys. Res. Lett. 39:18612.

Wijffels, S., and Meyers, G. (2004). An intersection of oceanic waveguides: variability in the Indonesian Throughflow region. J. Phys. Oceanogr. 34, 12321253. doi: 10.1175/1520-0485(2004)034<1232:aioowv>2.0.co;2

Wijffels, S. E., Beggs, H., Griffin, C., Middleton, J. F., Cahill, M., King, E., et al. (2018). A fine spatial scale sea surface temperature atlas of the Australian regional seas (SSTAARS): seasonal variability and trends around Australasia and New Zealand revisited. J. Mar. Syst. 187, 156-196. doi: 10.1016/j.jmarsys. 2018.07.005

Wijffels, S. E., Meyers, G. M., and Godfrey, J. S. (2008). A 20-year average of the Indonesian Throughflow: regional currents and the interbasin exchange. J. Phys. Oceanogr. 38, 1965-1978. doi: 10.1175/2008jpo3987.1

Wittenberg, A. T., Rosati, A., Lau, N., and Ploshay, J. J. (2006). GFDL's CM2 global coupled climate models. Part III: tropical pacific climate and ENSO. J.Clim. 19, 698-722. doi: 10.1175/jcli3631.1

Wyrtki, K. (1962). The upwelling in the region between Java and Australia during the South-East Monsoon. Aust. J. Mar. Freshw. Res. 13, 217-225.

Wyrtki, K. (1973). An equatorial jet in the Indian Ocean. Science 181, 262-264. doi: $10.1126 /$ science.181.4096.262

Wyrtki, K. (1987). Indonesian Throughflow and the associated pressure gradient. J. Geophys. Res. 92, 12941-12946. doi: 10.1029/JC092iC12p12941

Xu, T., Li, S., Hamzah, F., Setiawan, A., Susanto, R. D., Cao, G., et al. (2018). Intraseasonal flow and its impact on the Chlorophyll-A concentration in the Sunda Strait and its vicinity. Deep Sea Res. Part I Oceanogr. Res. Pap. 136, 84-90. doi: 10.1016/j.dsr.2018.04.003

Yang, J., Riser, S., Nystuen, J., Asher, W., and Jessup, A. (2015). Regional rainfall measurements using the Passive Aquatic Listener during the SPURS field campaign. Oceanography 28, 124-133. doi: 10.5670/oceanog.2015.10
Yoneyama, K., Zhang, C., and Long, C. N. (2013). Tracking pulses of the maddenJulian oscillation. Bull. Am. Meteorol. Soc. 94, 1871-1891. doi: 10.1175/bamsd-12-00157.1

Yuan, D., Li, X., Wang, Z., Li, Y., Wang, J., Yang, Y., et al. (2018). Observed transport variations in the Maluku Channel of the Indonesian Seas associated with western boundary current changes. J. Phys. Oceanogr. 48, 1803-1813. doi: 10.1175/JPO-D-17-0120.1

Yuan, D., Wang, J., Xu, T., Xu, P., Hui, Z., Zhao, X., et al. (2011). Forcing of the Indian Ocean dipole on the interannual variations of the tropical Pacific Ocean: roles of the Indonesian throughflow. J. Clim. 24, 3593-3608. doi: 10. 1175/2011jcli3649.1

Yuan, D., Zhou, H., and Zhao, X. (2013). Interannual climate variability over the tropical Pacific Ocean induced by the Indian Ocean dipole through the Indonesian Throughflow. J. Clim. 26, 2845-2861. doi: 10.1175/jcli-d-1200117.1

Yuan, D. L., and Wang, Z. (2011). Hysteresis and dynamics of a western boundary current flowing by a gap forced by impingement of mesoscale eddies. J. Phys. Oceanogr. 41, 878-888. doi: 10.1175/2010jpo4489.1

Zhang, N., Feng, M., Du, Y., Lan, J., and Wijffels, S. E. (2016). Seasonal and interannual variations of mixed layer salinity in the southeast tropical Indian Ocean. J. Geophys. Res. Oceans 121, 4716-4731. doi: 10.1002/2016JC0 11854

Zhou, H., Yuan, D., Yang, L., Li, X., and Dewar, W. (2018). Decadal variability of the meridional geostrophic transport in the upper tropical north pacific ocean. J. Clim. 31, 5891-5910. doi: 10.1175/jcli-d-17-0639.1

Zhou, X., Alves, O., Marsland, S. J., Bi, D., and Hirst, A. C. (2017). Multi-decadal variations of the South Indian Ocean subsurface temperature influenced by Pacific Decadal Oscillation. Tellus A Dyn. Meteorol. Oceanogr. 69:1308055. doi: 10.1080/16000870.2017.1308055

Zhuang, W., Feng, M., Du, Y., Schiller, A., and Wang, D. (2013). Low-frequency sea level variability in the southern Indian Ocean and its impacts on the oceanic meridional transports. J Geophys. Res. Ocean 118, 1302-1315. doi: 10.1002/jgrc. 20129

Conflict of Interest Statement: The authors declare that the research was conducted in the absence of any commercial or financial relationships that could be construed as a potential conflict of interest.

The reviewer TQ declared a past co-authorship with several of the authors, JS, AG, $\mathrm{SH}$, and DY, to the handling Editor .

Copyright (c) 2019 Sprintall, Gordon, Wijffels, Feng, Hu, Koch-Larrouy, Phillips, Nugroho, Napitu, Pujiana, Susanto, Sloyan, Peña-Molino, Yuan, Riama, Siswanto, Kuswardani, Arifin, Wahyudi, Zhou, Nagai, Ansong, Bourdalle-Badié, Chanut, Lyard, Arbic, Ramdhani and Setiawan. This is an open-access article distributed under the terms of the Creative Commons Attribution License (CC BY). The use, distribution or reproduction in other forums is permitted, provided the original author(s) and the copyright owner(s) are credited and that the original publication in this journal is cited, in accordance with accepted academic practice. No use, distribution or reproduction is permitted which does not comply with these terms. 